\title{
UN ANÁLISIS DE LA SEGURIDAD Y SALUD EN EL TRABAJO EN EL SISTEMA EMPRESARIAL CUBANO ${ }^{1}$
}

\author{
AN ANALYSIS OF SAFETY AND HEALTH AT WORK \\ IN THE CUBAN BUSINESS SYSTEM \\ UNE ANALYSE DE LA SECURITE ET LA SANTE AU TRAVAIL \\ DANS LE SYSTEME DE L'ENTREPRISE CUBAINE

\section{Gustavo Manuel CÉSPEDES SOCARRÁs Jorge Manuel MARTÍNEZ CUMBRERA ${ }^{3}$}

\begin{abstract}
RESUMEN: A partir de la existencia en Cuba de insuficiencias en los sistemas de gestión de la seguridad y salud en el trabajo (SGSST) en las empresas que pueden ser por la ocurrencia de incidentes y accidentes del trabajo con repercusiones en la responsabilidad social de las mismas. En este sentido la presente investigación tiene como objeto, el estudio de los SGSST, cuestión de gran importancia para el sector empresarial, pues en los momentos actuales dentro del ámbito empresarial a nivel internacional constituye un parámetro para determinar si una empresa es socialmente responsable, por lo que nuestro país no está ajeno de estas exigencias en el contexto empresarial.
\end{abstract}

Palabras clave: Incidentes y accidentes del trabajo, sistema de gestión de la seguridad y salud en el trabajo.

ABSTRACT: The evident structural lacking in our Security and Health in Labor Supporting Systems in enterprises remains being the direct consequence of accidents and incidents of or in occasion of labor with the corresponding influence in the social responsibility of these institutions. Therefore, this research aims to the objective of setting a real study of these systems so it could be definitely identified if they effectively contribute to qualify as

\footnotetext{
${ }^{1}$ Recibido el 7 de abril de 2015 y aceptado para su publicación el 9 de septiembre de 2015.

${ }^{2}$ Profesor asistente de la Universidad de Granma. Imparte las asignaturas de Derechos y obligaciones, y Derechos de contratos.

${ }^{3}$ Profesor asistente de la Universidad de Granma. Imparte las asignaturas de Derecho laboral y Seguridad social.jmartinezc@udg.co.cu.
} 
socially responsible enterprises.

Keys Words. Accidents and Incidents of or in Occasion of Labor, Security and Health in Labor Supporting Systems.

RESUME: A partir de l'existence à Cuba des insuffisances dans le Système de gestion de santé et sécurité au travail (SGSST selon son sigle en espagnol) aux entreprises où peuvent être provoqués des incidents et accidents du travail, en ce qui concerne leur responsabilité sociale. À cet égard, l'objectif de la recherche est analyser du SGSST, celui-ci d'une grande importance dans le secteur des entreprises, puisque, au ce moment dans le domaine des entreprises au niveau international, le SGSST constitue un paramètre afin de déterminer si une des entreprises est socialement responsable, donc, notre pays n'est pas excepté des contraintes de responsabilité social.

Mots-clés: Incidents et accidents du travail, système de gestion de santé et sécurité au travail.

SUMARIO: I. Introducción. II. Elementos que configuran los sistemas de gestión de la seguridad y la salud en el trabajo. III. Principales insuficiencias de los sistemas de gestión de la seguridad y salud en el trabajo. IV. Presupuestos teóricos para el perfeccionamiento de los sistemas de gestión de la seguridad y salud en el trabajo. V. Conclusiones. VI. Recomendaciones.

\section{INTRODUCCIÓN}

La seguridad y la salud en el trabajo han sido tema de interés en las diferentes etapas del desarrollo histórico de la sociedad, por lo que la formalización de sus métodos y fines, así como su cuerpo teórico, son el resultado de la producción investigativa de profesionales de diferentes especialidades. Sin embargo, todavía existen limitaciones que deben ser superadas con la misma rapidez con que se ha desarrollado en los siglos XX y XXI, caracterizados por las nuevas necesidades derivadas del empleo de las tecnologías de la información y la comunicación (TIC), así como los nuevos contextos laborales donde predominan las exigencias mentales sobre las físicas.

En ocasiones, los sistemas de gestión de la seguridad y salud en el trabajo implementados en nuestras empresas no cumplen su objetivo fundamental, que es el de disminuir o evitar la ocurrencia de incidentes, 
accidentes de trabajo y de enfermedades profesionales, lo cual responde básicamente a las inminentes insuficiencias que muestran la implementación de este sistema en las empresas y por consiguiente la inadecuada aplicación de la responsabilidad social empresarial (RSE). Estas deficiencias y otras que persisten en nuestra economía, constituyeron los fundamentos para la elaboración de los lineamientos de la política económica y social, aprobados en el VI Congreso del Partido Comunista Cubano en 2011, existiendo una estrecha correspondencia del tema objeto de investigación y los lineamientos, específicamente el $134^{4} \mathrm{y}$ $137,{ }^{5}$ encaminados a lograr el desarrollo del país y con esto el bienestar de la sociedad cubana.

La seguridad y la salud en el trabajo han sido abordadas en nuestro país desde diferentes aristas, siendo los aspectos más trascendentales lo concerniente a: exposición a riesgos laborales, el estudio de los accidentes de trabajo, el ambiente laboral y la morbilidad laboral temporal, cuestión corroborada a través del estudio de las tesis defendidas en la maestría en salud ocupacional, en el periodo comprendido entre 1984-2006, lo que nos permitió comprender que estas investigaciones precedentes realizaron importantes aportes a la seguridad y salud ocupacional, laboral o del trabajo pero no se propusieron como objetivo directo el análisis de los sistemas de gestión de la seguridad y salud en el trabajo (SGSST), sino que abordaron esta temática desde otras aristas o por las propias particularidades de cada una de estas investigaciones no excluyeron la posibilidad de seguir estudiando el tema en el orden académico, unido a esto se encuentran los trabajos de diplomas realizados por Cruz Romera y

\footnotetext{
${ }^{4}$ Lineamiento 134: Las entidades económicas en todas las formas de gestión contarán con el marco regulatorio que propicie la introducción sistemática y acelerada de los resultados de la ciencia, la innovación y la tecnología en los procesos productivos y de servicios, teniendo en cuenta las normas de responsabilidad social y medioambiental establecidas.

5 Lineamiento 137: Continuar fomentando el desarrollo de investigaciones sociales y humanísticas sobre los asuntos prioritarios de la vida de la sociedad, así como perfeccionando los métodos de introducción de sus resultados en la toma de decisiones a los diferentes niveles.
} 
Esta revista forma parte del acervo de la Biblioteca Jurídica Virtual del Instituto de Investigaciones Jurídicas de la UNAM

Labrada Marro, $^{6}$ en los que se hace una análisis a los SGSST en la entidades referidas, pero se quedan en el plano de identificar las deficiencias sin llegar a dar propuestas para su perfeccionamiento.

Por su parte, Miranda Hernández y Santana Pascual $^{7}$ en sus tesis de maestrías, hacen una propuesta de diseño e implementación de un sistema integrado de la calidad, dentro de la cual tocan de manera sucinta lo referente a la seguridad y salud en el trabajo como parte de ese sistema integrado que proponen. En otro orden, Rojas Casas ${ }^{8}$ plantea una metodología para el cálculo de los accidentes de trabajo que facilitará un mayor control estadístico sobre los mismos en la industria azucarera de Holguín; por último, se encuentra la tesis doctoral de Velázquez Zaldívar ${ }^{9}$ en la que alude a un modelo de mejora continua para la gestión de la

${ }^{6}$ Véase Cruz Romera, Dunia Esther, “Diagnóstico al sistema de gestión de la seguridad y salud ocupacional en la empresa comercializadora y distribuidora de medicamentos Droguería Holguín", Trabajo de diploma, Facultad de ingeniería Industrial y Turismo, Universidad de Holguín "Oscar Lucero Moya”, 2009; Labrada Marro, Dagoberto, “Diagnóstico al sistema de gestión de la seguridad y salud ocupacional en la empresa productora y distribuidora de alimento Calixto García", Trabajo de diploma, Facultad de Ingeniería Industrial y Turismo, Universidad de Holguín “Oscar Lucero Moya”, curso 2008-2009.

${ }^{7}$ Miranda Hernández, Celia, “Diseño de un sistema integrado de gestión de calidad, medio ambiente, seguridad y salud en el trabajo en la empresa de plaguicidas «Juan Luis Rodríguez Gómez»", Tesis en opción al grado científico de Máster en Ciencias Técnicas, Instituto Superior Politécnico "José Antonio Echeverría", Facultad de Ingeniería Industrial, junio de 2012; Santana Pascual, Kenia, “Diseño e implantación del sistema integrado de gestión de calidad, medio ambiente, seguridad y salud en el trabajo", Tesis en opción al grado científico de Máster en Ciencias Técnicas, Instituto Superior Politécnico "José Antonio Echeverría”, Facultad de Ingeniería Industrial, junio de 2012.

${ }^{8}$ Véase Rojas Casas, Ricardo D., “Los accidentes del trabajo en la Industria Azucarera de Holguín", Tesis presentada en opción al título académico de Máster en Matemática Aplicada e Informática para la Administración, Universidad de Holguín "Oscar Lucero Moya", Facultad de Ingeniería Industrial, Holguín, 2001.

${ }^{9}$ Velázquez Zaldívar, Reynaldo, “Modelo de mejora continua para la gestión de la seguridad e higiene ocupacional. Aplicaciones en empresas de la industria alimenticia", Tesis presentada en opción al grado científico de Doctor en Ciencias Técnicas, La Habana, Instituto Superior Politécnico "José Antonio Echeverría”, Facultad de Ingeniería Industrial, Departamento de Ingeniería Industrial, 2002. 
seguridad e higiene ocupacional, con base fundamentalmente en la industria alimenticia.

Por tanto, del estudio realizado en la doctrina cubana a partir de las investigaciones referidas, se puede comprobar que ninguna hace alusión a la responsabilidad social empresarial y mucho menos a la relación que existe entre los sistemas de gestión de la seguridad y salud en el trabajo; por lo que el aporte de investigación va encaminado a demostrar la vinculación existente entre la RSE y el derecho laboral, específicamente con los sistemas de gestión de la seguridad y salud en el trabajo, así como la incidencia que tienen éstos en las empresas, con vistas a que sean socialmente responsables.

En este sentido, a partir del diagnóstico realizado a los SGSST en las empresas seleccionadas del municipio Bayamo, nos permitió dilucidar la existencia de insuficiencias que persisten en el momento de dimensionar y estructurar sus elementos, los riesgos laborales a que están expuestos los trabajadores, así como la función que desempeñan los sujetos en cada una de las fases de su elaboración, implementación y control, cuestiones que inciden de manera negativa en la correcta aplicación de la responsabilidad social empresarial y en la concepción de esta categoría dentro de los SGSST en estas empresas.

Lo antes expuesto nos permite proponer como problema científico al planteamiento siguiente: las insuficiencias en la concepción de los sistemas de gestión de la seguridad y salud en el trabajo en el ordenamiento jurídico laboral cubano, generan una inadecuada aplicación de la responsabilidad social empresarial incidente en el papel protector del derecho laboral. Se declara como objeto de investigación: los sistemas de gestión de la seguridad y salud en el trabajo, y como campo: la responsabilidad social empresarial y se toma como muestra: las empresas en perfeccionamiento empresarial: Pasteurizadora "El Alba", el Combinado Lácteo, La Hacienda, la Empresa de Bebidas y Refrescos, la Embotelladora de Cervezas y la UEB de Bayamo perteneciente al Laboratorio Farmacéutico Oriente.

Viendo a la concepción como una categoría híbrida, conformada por diversos procesos: organización, elaboración, implementación, 
supervisión y sistematización, mereciendo cada uno de ellos un estudio independiente. Las irregularidades en cualquiera de estos procesos van en detrimento con el cumplimiento de la finalidad de los sistemas de gestión de la seguridad y salud en el trabajo. Tales procesos están marcados por la pluralidad de los elementos conformadores de dicho sistema, por lo que se precisa de una armonía entre sí.

Para la posible solución del problema científico se propone como objetivo general: fundamentar, a partir de un estudio doctrinal, legis/ativo y comparado, la configuración de los presupuestos jurídicos de aplicación de los sistemas de gestión de la seguridad y salud en el trabajo, en pos de su perfeccionamiento y de la adecuada aplicación de la responsabilidad social empresarial en el ordenamiento jurídico cubano, contribuyendo a una mayor protección de la fuerza de trabajo.

La investigación se desglosó en dos capítulos que se corresponden con los objetivos específicos siguientes:

1. Sistematizar los fundamentos teóricos, históricos y de proyección comparada conformadores de la seguridad y salud en el trabajo que permitan fijar pautas doctrinales en torno a su relación con la dimensión laboral de la responsabilidad social empresarial.

2. Establecer los presupuestos jurídicos de los sistemas de gestión de seguridad y salud en el trabajo para una adecuada aplicación de la responsabilidad social empresarial, a partir del diagnóstico de las insuficiencias que presentan las empresas perfeccionadas del municipio Bayamo, en correspondencia con la doctrina y el ordenamiento jurídico cubano.

La realización de esta investigación estuvo sustentada en la utilización de los principales métodos empleados en las ciencias jurídicas, y en especial los propuestos por Pavó Acosta, ${ }^{10}$ siendo enunciados de una manera integrada y combinada, adaptándolos a los fines propios de la

\footnotetext{
${ }^{10}$ Véase Pavó Acosta, Rolando, Introducción a la metodología de la investigación jurídica, Santiago de Cuba, Facultad de Derecho, Universidad de Oriente, 2003; id., La investigación científica del derecho, Lima, Universidad Inca Garcilaso de la Vega-Fondo Editorial Nuevos Tiempos. Nuevas Ideas, 2009.
} 
investigación:

Métodos teóricos de la investigación.

— Análisis, síntesis, inducción, deducción: útiles en la realización del estudio teórico-jurídico, para caracterizar al ordenamiento jurídico laboral y apreciar el estado de la ciencia en cuanto a los sistemas de gestión de la seguridad y salud en el trabajo así como de la responsabilidad social empresarial.

Métodos teórico-jurídicos.

- Histórico-jurídico: para analizar a través de una secuencia lógica la génesis, evolución y estado actual de la responsabilidad social empresarial, así como su relación con los sistemas de gestión de la seguridad y salud en el trabajo, teniendo como sustento el conjunto de normas jurídicas tanto a nivel internacional como nacional referente a dicho particular.

- Análisis exegético-jurídico: para analizar las diferentes normas jurídicas cubanas e internacionales en materia laboral que regulan los sistemas de gestión de la seguridad y salud en el trabajo, evaluando de manera exhaustiva el lenguaje empleado, la técnica jurídica utilizada y la identificación de las deficiencias relacionadas con los presupuestos teóricos de los sistemas de gestión de la seguridad y salud en el trabajo.

- Método de derecho comparado: para destacar semejanzas y diferencias, establecer clasificaciones, descubrir tendencias en cuanto a la regulación de la responsabilidad social empresarial y su dimensión laboral, específicamente relacionada con la seguridad y salud en el trabajo, a partir de las condicionantes sociohistóricas y culturales en las que está inmersa.

De los métodos empíricos, el análisis de contenidos: que posibilitó la construcción del marco histórico y contextual del objeto de la investigación, incluyendo la revisión de textos, publicaciones de prestigio de diversos autores foráneos y nacionales, normas jurídicas internacionales y de los distintos sistemas de derecho, lo que permitirá dar una explicación de las tendencias que se presentan en torno a la 
responsabilidad social empresarial con respecto a su dimensión laboral, así como formarnos un criterio sobre las posiciones doctrinales de los autores, resultando discreta la bibliografía relativa al tema en el país. Fueron utilizadas como técnicas de este método, las encuestas aplicadas en cada una de las empresas tomadas como muestra.

Como principales resultados se pretende obtener:

- Sistematización teórico-doctrinal sobre la responsabilidad social empresarial, específicamente en torno a su dimensión laboral, con determinación de pautas metodológicas para su regulación en un cuerpo normativo.

- Sistematización del desarrollo de los sistemas de gestión de la seguridad y salud en el trabajo en Cuba y recopilación de las normas jurídicas asociadas con el tema en la historiografía cubana.

- Configuración de los presupuestos teóricos de los sistemas de gestión de la seguridad y salud en el trabajo, como sustento para su perfección.

- Material bibliográfico actualizado sobre la responsabilidad social empresarial y de los sistemas de gestión de la seguridad y salud en el trabajo.

Las disposiciones jurídicas normativas extranjeras analizadas en la investigación, en materia de derecho laboral, se seleccionaron teniendo en cuenta el sistema de derecho, las raíces comunes, el idioma y los aportes realizados a los institutos y categorías del derecho laboral examinadas, específicamente en la forma de normar la dimensión laboral de la responsabilidad social empresarial. De igual manera, los criterios de los diferentes autores referidos en la investigación, nos permitieron esgrimir las divergencias o las convergencias existentes con la nuestra; planteamos y demostramos la relación de la responsabilidad social empresarial con el derecho laboral o del trabajo, particularmente con respecto a la seguridad y salud en el trabajo; quizás sea una ponderación de nuestra parte, pero la polémica que se genere por tal afirmación resultará beneficiosa para la ciencia jurídica en general, y en especial para la rama del derecho empresarial y dentro de ella, para el derecho laboral. 


\subsection{Premisas jurídicas y sociohistóricas de la regulación de la seguridad} y salud en el trabajo como medidor de la responsabilidad social empresarial en el ordenamiento jurídico laboral cubano

El componente histórico posibilita en la presente investigación, no sólo sentar las pautas importantes en la historia del campo de estudio propuesto, sino que permite proyectar asimismo la interrelación precedente entre la RSE y los SGSST, además de los cambios previos en ordenamiento jurídico laboral cubano vigente, a partir de la actualización del modelo económico-social del país. En esta sistemática se impone un breve tratamiento de los antecedentes del actual ordenamiento laboral cubano, con referencia más pormenorizada a la SST, como institución importante en el contexto empresarial, en la conducta ciudadana y en el desarrollo económico social.

De tal análisis emergen elementos permisivos de una comprensión de las actuales características de la SST, a partir de una revolución en la regulación laboral determinante de su constitución en el punto de mira del debate científico jurídico; sobre todo, la constatación de las principales deficiencias en esta materia no es un problema nuevo. La regulación de la SST en Cuba ha transitado por cuatro etapas ${ }^{11}$ fundamentales:

La primera se enmarca en el periodo neocolonial, cuando la legislación vigente sólo establecía algunos servicios médicos curativos para centros de trabajo de importancia y seguros sociales a muy pocos trabajadores, que no cubrían todos los riesgos. En este sentido, la Ley de Accidentes de Trabajo de 12 de junio de $1916,{ }^{12}$ marca una trascendencia en esta etapa en cuanto a la temática tratada; en ella se dejaba por sentado la responsabilidad que tenían los patronos en cuanto a garantizarle las condiciones seguras a sus obreros para laborar, por lo que debían de asegurarlos contra todo acontecimiento y en caso de ocurrencia de algún

\footnotetext{
${ }^{11}$ Véase Colectivo de Autores, Seguridad y Salud en el Trabajo, La Habana, Félix Varela, 2012.

${ }^{12}$ López Castillo, Raúl, Accidentes de trabajo (Cuba), Molina y Cía., obra premiada con Mención Honorífica y Medalla de Plata en el Concurso Anual del Colegio de Abogados de La Habana, 1930, Ricla 55-57, pp. 7-75.
} 
accidente de trabajo, la forma en que debían de proceder para exigir la correspondiente indemnización derivada de tal acontecimiento e incluso podía aumentarse la indemnización si se comprobaba que el accidente es debidamente a falta inexcusable del patrono de quienes lo sustituyera, en igual sentido regulaba que el empresario o su representantes estaban obligados dentro del término de 24 horas siguientes a informar al juez municipal del distrito, ${ }^{13}$ quien daba al participante recibo del aviso ${ }^{14} \mathrm{y}$ del certificado médico y ponía el accidente en conocimiento de la Compañía de Seguros en el supuesto de que el obrero estuviese asegurado, así como al alcalde municipal del término donde hubiese ocurrido el accidente.

Esta Ley fue rígidamente protectora del obrero, estableciendo que sus derechos a la indemnización eran irrenunciables; sin embargo, en la oportunidad de cobrarla la abandona, pues resultaba más alarde que realidad no poder renunciar a esos derechos, la razón se sustentaba en que el propio cuerpo de la norma permitía la flexibilidad en este aspecto y los derechos irrenunciables, a criterio de este autor, no pueden nunca negociarse y mucho menos ser flexibles; lo justo y equitativo, según el principio rígido que establecía esta normativa, sería condenar al pago de las indemnizaciones ${ }^{15}$ exactas a que tuviesen derecho los obreros.

\footnotetext{
${ }^{13}$ Cfr. Artículos I, X, XI, XIII, XXIII y XXV de la Ley Accidentes de Trabajo de 12 de junio de 1916, promulgada en la Gaceta Oficia/del 16 de junio de 1916.

${ }^{14}$ Este aviso contenía los nombres de la víctima, de los testigos del accidente e iba acompañado de un certificado médico indicando el estado de la víctima, la consecuencia probable del accidente y en la época en la cual, a su juicio, será posible conocer el resultado definitivo.
}

${ }^{15}$ Con respecto a las indemnizaciones por accidentes de trabajo es oportuno hacer referencia a determinadas sentencias emitidas por los Tribunales de Primera Instancia y el Tribunal Supremo en la década de los veinte, en las cuales se evidencia la flexibilidad con respecto al ejercicio de este derecho; $v$. gr. Sentencia núm. 162 del 18 de septiembre de 1929 del Supremo, Sentencia núm. 137, del 30 de septiembre de 1926 y la Sentencia núm. 31 del 2 de marzo de 1925, en esta última sentencia fue muy debatida ese tiempo y marcó una pauta importante en la doctrina cubana de aquella época, en cuanto a que se declaró sin lugar la reclamación de la indemnización realizada por los familiares del obrero Simón Surís y Abrahante (sereno de los almacenes de azúcar de la Munson Line, Matanzas, en la noche del 16 de agosto de 1921) fallecido en ocasión de estar prestando sus servicios, por lo que el juez de Primera Instancia de Matanzas dictó sentencia estimando que era el 
Por su parte, el Decreto núm. 798 de $1938^{16}$ (Reglamento de los Contratos de Trabajo) regulaba en su capítulo I "Del Contrato de Trabajo", todas las cuestiones relacionadas con este tópico, dígase, requisitos, tipos, así como las funciones y obligaciones tanto de los obreros como de los patronos y en este sentido refiere a que una de las funciones del patrono es proporcionar condiciones de trabajo seguras a los obreros. ${ }^{17}$

La ponderada Constitución de 1940 estableció los seguros sociales como derecho irrenunciable e imprescindible de los trabajadores, el carácter obligatorio el seguro por accidentes del trabajo y enfermedades profesionales, a expensas exclusivamente de los patronos y bajo la fiscalización del Estado, ${ }^{18}$ la protección a la maternidad obrera ${ }^{19}$ y la responsabilidad por parte del patrono del cumplimiento de las leyes sociales. $^{20}$

La segunda se ubica entre 1959 y 1990, donde se dictan importantes legislaciones, entre ellas podemos citar la Ley Fundamental de 1959 que

Tribunal de lo Criminal quien debía fijar la indemnización en su día, cuestión ésta que no era la más acertada, pues el procedimiento correcto era que la jurisdicción de lo civil tramitara la pretensión de los familiares, porque en caso de que por la vía criminal no había nadie a quien cobrárselo, entonces se atraía al patrón por la vía civil para que lo protegiera de acuerdo con los preceptos de la mencionada Ley de Accidentes de Trabajo, pues el accidente ocurrió sirviéndole a él.

${ }^{16}$ Publicado en la Gaceta Oficia/del 27 de mayo de 1938.

${ }^{17}$ Cfr. Artículo 23. Son obligaciones del patrono: c) proporcionar locales de trabajo, maquinarias y herramientas en las condiciones debidas de seguridad y eficiencia.

18

Véase Constitución de la República de Cuba de 5 de julio de 1940, disponible en http://moodle.udg.co.cu/pluginfile.php/3542/mod_folder/content/0/Constitucion_Cuba_19 40.htm?forcedownlad=1, artículo 65 del texto constitucional.

${ }^{19}$ Idem. Artículo 68. La ley regulará la protección a la maternidad obrera, extendiéndola a las empleadas. La mujer grávida no podrá ser separada de su empleo, ni se le exigirá efectuar, dentro de los tres meses anteriores al alumbramiento, trabajos que requieran esfuerzos físicos considerables.

${ }^{20}$ Idem. Artículo 78. El patrono será responsable del cumplimiento de las leyes sociales, aun cuando contrate el trabajo por intermediario. En todas las industrias y clases de trabajo en que se requieran conocimientos técnicos, será obligatorio el aprendizaje en la forma. 
Esta revista forma parte del acervo de la Biblioteca Jurídica Virtual del Instituto de Investigaciones Jurídicas de la UNAM

mantuvo aspectos establecidos en su antecedente inmediato, la Constitución de 1940, cítese los seguros sociales, ${ }^{21}$ la protección a la maternidad obrera ${ }^{22}$ y hace alusión a que el Estado proveerá a la vigilancia e inspección de las empresas; ${ }^{23}$ la Constitución de $1976,{ }^{24}$ en la cual quedaba reconocido que mediante el sistema de seguridad social, el Estado garantizaba la protección adecuada a todo trabajador impedido por su edad, invalidez o enfermedad, en caso de muerte del trabajador aseguraba similar protección a su familia; asimismo el Estado garantizaría el derecho a la protección, seguridad e higiene del trabajo, mediante la adopción de medidas adecuadas para la prevención de accidentes y enfermedades profesionales y el que sufriera un accidente en el trabajo o contrajera una enfermedad profesional, tenía derecho a la atención médica y a subsidio o jubilación en los casos de incapacidad temporal o permanente para el trabajo.

La derogada Ley 13 de 1977 de Protección e Higiene del Trabajo (PHT) ${ }^{25}$

21 Véase Ley Fundamental del 7 de febrero de 1959, disponible en http://moodle.udg.co.cu/pluginfile.php/3542/mod_folder/content/O/ley_fundamental_1959 _.htm?forcedownload=1, artículo 65. Se establecen los seguros sociales como derecho irrenunciable e imprescriptible de los trabajadores, con el concurso equitativo del Estado, los patrones y los propios trabajadores, a fin de proteger a éstos de manera eficaz contra la invalidez, la vejez, el desempleo y demás contingencias del trabajo, en la forma que la ley determine.

22 Idem. Artículo 68. No podrá establecerse diferencia entre casadas y solteras a los efectos del trabajo. La ley regulará la protección a la maternidad obrera, extendiéndola a las empleadas. La mujer grávida no podrá ser separada de su empleo, ni se le exigirá efectuar, dentro de los tres meses anteriores al alumbramiento, trabajos que requieran esfuerzos físicos considerables.

23 Idem. Artículo 85. A fin de asegurar el cumplimiento de la legislación social, el Estado proveerá la vigilancia e inspección de las empresas.

${ }^{24}$ Véase Constitución de la República de Cuba de 24 de febrero de 1976, disponible en http://moodle.udg.co.cu/pluginfile.php/3542/mod_folder/content/0/Constitucion_Cuba_19 76.htm?forcedownload=1, artículos 46 y 48 .

${ }^{25}$ Ley núm. 13/1977 “Protección e higiene del trabajo", promulgada por la Asamblea Nacional de Poder Popular y publicada en la Gaceta Oficial Ordinaria, núm. 48, 29 de diciembre de 1977, derogada por la Ley 116 “Código de Trabajo” de 2013. 
(que establecía los principios fundamentales que rigen el sistema de protección e higiene del trabajo, las obligaciones, atribuciones y funciones de los organismos rectores en esta materia y también de las funciones de las administraciones. En su articulado se reconocía los derechos y deberes de los trabajadores y la función que debe ejercer la organización sindical como garante en la protección e higiene en el trabajo) y el Decreto 101 de 1982 “Reglamento General de la Ley de Protección e Higiene del Trabajo”26 (en la que se regulaba que los trabajadores deberían recibir las instrucciones de protección e higiene del trabajo para la realización de su actividad laboral en condiciones seguras, mediante la impartición de los conocimientos sobre las reglas de protección e higiene del puesto de trabajo en el que laboraran y sobre las condiciones generales de la entidad en que trabajasen, de igual manera refiere que el adiestramiento constituye una forma capaz de brindar a los dirigentes, técnicos y demás trabajadores, los conocimientos en relación con los diferentes aspectos de la protección e higiene del trabajo), estas normas derogadas en la práctica jurídica cubana marcaron un avance significativo en esta actividad.

En cuanto a la tercera etapa, se enmarca en los años de la década de los noventa, cuando al igual que otras actividades, sufrió un deterioro abrumador; ya que el país no pudo dar respuestas a las exigencias de las condiciones de la seguridad y salud en trabajo, sobre todo en lo concerniente a los medios de producción, con esto aparece la producción de algunos medios de protección por parte de industria locales de los municipios, aunque no sufragaban todas las necesidades existentes al menos trataban de solventar la situación imperante en esa década.

La cuarta se concentra a finales de los años noventa e inicios del 2000, donde se revitaliza con fuerza la actividad de la seguridad y salud en el trabajo, aplicándose nuevos conceptos de seguridad integrada e integral, ${ }^{27}$

\footnotetext{
${ }^{26}$ Aprobado por el Consejo de Ministro y promulgado en la Gaceta Oficial Extraordinaria, núm. 13, 3 de abril de 1982.

${ }^{27}$ Integrada porque incorpora los objetivos y tareas del medio ambiente de trabajo a las funciones de cada área y miembro de la organización en la entidad, caracterizada por la efectividad y rentabilidad pues prescinde de la existencia de un gran aparato de seguridad. Integral porque se encamina a suprimir el riesgo en todas sus manifestaciones posibles, es
} 
unido a la promulgación de numerosas normas jurídicas que coadyuvarían a solventar el deterioro existente en nuestro país, producto a la caída del campo socialista y el fortalecimiento del bloqueo económico del gobierno estadounidense, en torno a esta problemática, es válido resaltar la puesta en vigor del Decreto Ley $252^{28}$ (Perfeccionamiento empresarial) y el Decreto núm. 281 relacionado con el perfeccionamiento empresarial ${ }^{29}$ así como de la Resolución núm. 39 “Bases generales de la protección, seguridad e higiene del trabajo", 30 en esta resolución rigen los principios generales siguientes: la responsabilidad a todos los niveles de los jefes de las entidades laborales con la seguridad y salud de los trabajadores; la prevención de los incidentes, accidentes de trabajo, incendios, explosiones y enfermedades profesionales y otros daños a la salud en el ámbito laboral; la protección especial a mujeres, jóvenes, trabajadores con reducción de su capacidad laboral, así como a los que contraen enfermedades profesionales o sufren accidentes de trabajo y la protección del patrimonio de la entidad y del medio ambiente; todas estas disposiciones jurídicas normativas fueron promulgadas en 2007.

Aunque la Ley 81/1997 Ley de Medio Ambiente, ${ }^{31}$ no es una norma específica para el ámbito laboral, sí es oportuno hacer alusión a que dedica el título decimocuarto a la protección del medio ambiente en las actividades laborales y obliga a los empleadores a asegurar condiciones ambientales que no afecten o pongan en riesgo la salud o la vida de los trabajadores y a desarrollar las actividades en armonía con el medio

decir, no sólo en lo que concierne a los tradicionales riesgos y daños para el hombre, sino asimismo en lo que se refiere al entorno, al grado de satisfacción del trabajador, etcétera.

${ }^{28}$ Aprobado por el Consejo de Estado y promulgado en la Gaceta Oficial Extraordinaria, núm. 41, 17 de agosto de 2007.

${ }^{29}$ Idem.

${ }^{30}$ Aprobada por el Ministerio de Trabajo y Seguridad Social y promulgada en la Gaceta Oficial Ordinaria, núm. 54, 20 de agosto de 2007, derogada por el Decreto núm. 326 de 2014 "Reglamento del Código de Trabajo", publicado en la Gaceta Oficial Extraordinaria, núm. 29 de 17 de junio de 2014 en su disposición final cuarta, numeral 68, p. 520.

${ }^{31}$ Aprobada por la Asamblea Nacional del Poder Popular y promulgada en la Gaceta Oficial Extraordinaria, núm. 7, 11 de julio de 1997. 
ambiente sin dejar de garantizar los medios de protección necesarios para laborar. Este título está muy a tono con la idea que en los contextos actuales se defiende en los escenarios internacionales y es lo referente al llamado desarrollo sostenible, que se traduce en seguridad para los trabajadores de hoy sin poner en peligro la de las generaciones futuras; pero la relación debe ser de retroalimentación; no sólo las regulaciones ambientales deben tratar el entorno laboral, sino también desde la perspectiva de las leyes específicas de salud y seguridad del trabajo es vital que se integren en cada objetivo los propósitos de la protección del medio ambiente.

A tono con esto, la Resolución 31 de fecha julio del 2002 del Ministerio de Trabajo y Seguridad Social (MTSS) ${ }^{32}$ regulaba la identificación, evaluación y control de los factores de riesgos presentes en las áreas y puestos de trabajo que afecten o que puedan afectar la seguridad o la salud de los trabajadores. La identificación y evaluación de riesgos como elemento fundamental de los programas de prevención que debe tener cada organización para disminuirlos o eliminarlos; el orden, la limpieza y la higiene, son direcciones en las cuales en la actualidad se dirige la acción en la seguridad y salud en el trabajo, lo que permite ir sincronizando en nuestro medio una cultura de trabajo seguro. De ahí parte también el empeño del Estado de lograr que nuestros trabajadores laboren en condiciones sanas y seguras que permitan una gestión eficaz y eficiente.

Por su parte, la Resolución 19 de 8 de septiembre del 2003, ${ }^{33}$ también con un fuerte carácter, preventivo establece la obligatoriedad para todos los organismos de la administración central del Estado, los órganos del poder popular, las empresas, unidades presupuestadas, cooperativas y demás organizaciones económicas y sociales y sus representantes, así como, el sector privado de la economía al registro, investigación e información de los accidentes de trabajos que ocurran durante las

\footnotetext{
${ }^{32}$ Aprobada por el Ministerio de Trabajo y Seguridad Social y derogada por el Decreto núm. 326 de 2014 "Reglamento del Código de Trabajo", publicado en la Gaceta Oficial Extraordinaria, núm. 29, de 17 de junio de 2014 en su disposición final cuarta, numeral 50, p. 519.
}

${ }^{33}$ Ibidem, numeral 52, p. 519. 
actividades laborales que originen lesiones o incapacidades de al menos un día o turno de trabajo completo, además de aquel en que ocurrió el accidente. Tampoco puede obviarse las normas cubanas 18000, 18001, 18002 y 18011 de 2005 enfocadas a los SGSST, en el sentido de establecer requisitos, vocabularios, elementos y auditorías aplicables en el sistema antes acotado.

De igual manera resulta pertinente mencionar la Resolución 51 de 2008 donde se establecía la metodología para la elaboración del Manual de Seguridad en el Trabajo, ${ }^{34}$ el cual era puesto en vigor a través de resolución emitida por el jefe máximo de la entidad, previa consulta con la organización sindical correspondiente, este Manual se adecuaba en las unidades y centros de trabajo que se le subordinan a la entidad, en correspondencia con sus características y funciones, cumpliendo con lo establecido en la legislación vigente y se aprobaba por la dirección de la entidad.

En esta misma línea explicativa, este investigador considera que se debe agregar otra etapa, situada a partir del 6o. Congreso del Partido Comunista de Cuba con la puesta en vigor de los lineamientos de la política económica y social del país, lo que trajo consigo la actualización de nuestro modelo económico y con ello la promulgación de nuevas normas jurídicas atemperadas al contexto cubano actual, ejemplos fehacientes de esto lo constituyen la Ley 116 "Código de Trabajo"35 y el Decreto núm. 326 "Reglamento del Código de Trabajo" aprobados en $2013^{36}$ y que unifican la dispersión existente en el país hasta el momento en materia laboral.

Si bien, por un lado el nuevo Código de Trabajo unifica la dispersión que en materia laboral existía en nuestro ordenamiento jurídico y constituye un logro positivo en este orden; por otro, no establece una

\footnotetext{
${ }^{34}$ Ibidem, numeral 72, p. 520.

${ }^{35}$ Aprobado por la Asamblea Nacional del Poder Popular a los 20 días de diciembre de 2013 y promulgado en la Gaceta Oficial Extraordinaria, núm. 29, del 17 de junio de 2014.

${ }^{36}$ Aprobado por el Consejo de Ministros de la República de Cuba y promulgado en la Gaceta Oficial Extraordinaria, núm. 29, 17 de junio de 2014.
} 
sistematicidad en cuanto a los principios básicos que rigen la seguridad y salud en el trabajo, tal situación puede provocar flagrante violación en la apreciación e integración social de esta categoría, trascendente a la unidad y plenitud de su regulación jurídica, siendo una deficiencia que en la materia laboral aún persisten en nuestra norma general. De igual manera en esta norma se establecen los derechos y deberes que tienen las partes y la función que deben ejercer los organismos rectores de esta materia, con respeto a este apartado es válido aclarar que el nuevo Código utiliza el término de empleador, incluyendo en este concepto tanto a las personas jurídicas como naturales, la inclusión de estas últimas personas se debe al auge que han alcanzado en nuestro contexto económico-social el sector no estatal.

En este mismo orden también establece que el trabajador tiene derecho a laborar en condiciones seguras e higiénicas, aludiendo a que éstos participan en la identificación y evaluación de los riesgos en el trabajo y cumplen las medidas indicadas para prevenir accidentes y enfermedades profesionales, por lo que tienen el derecho a recibir las instrucciones sobre la seguridad y salud en el trabajo.

A tenor con esto, refrenda el derecho especial que regulaba la derogada Ley 13 de 1977 "Protección e Higiene del Trabajo", en el ámbito de que el trabajador puede negarse a laborar en su puesto de trabajo, ya no bajo el título de derecho especial pero sí establece su contenido íntegro tal y como lo establecía la mencionada ley. ${ }^{37}$ Aparece expresamente que la elaboración, aprobación y control del cumplimiento de los reglamentos y normas en materia de seguridad y salud en el trabajo está a cargo de los ministerios que dirigen y controlan las políticas en los distintos sectores, ramas y actividades, así como los organismos que integran el sistema nacional de educación y otros que atienden integralmente la formación técnico-profesional y superior, garantizan en los planes de estudios, la integración de los contenidos generales y específicos sobre la seguridad y salud en el trabajo.

La disposición final segunda de la Ley núm. 116/2014 ensombrece la

${ }^{37}$ Cfr. Artículo 139 de la Ley 116 de 2014 "Código de Trabajo". 
reserva de Ley al refrendar que el ministro de Trabajo y Seguridad Social y los jefes de los organismos rectores a que se refiere la presente Ley, quedan encargados de dictar en el ámbito de sus competencias, las disposiciones necesarias para el mejor cumplimiento de este Código. Resulta extremadamente peligroso, desde el punto de vista del autor, la remisión a la potestad reglamentaria a los jefes de organismos, en el sentido de dictar las disposiciones necesarias dentro de su ámbito de la competencia, que contribuyan al mejor cumplimiento del Código, esto puede traer consigo que no exista una uniformidad en cuanto a estas disposiciones, conllevando incluso a interpretaciones contrarias a lo que establece esta norma por parte de estos jefes, aunque esto parezca algo descabellado pero la praxis jurídica nos lo ha demostrado. Sin embargo, comparto con lo regulado en el Decreto núm. 326/2014 en su disposición final primera, que faculta al Ministerio de Trabajo y Seguridad Social para que dicte las disposiciones necesarias para la mejor aplicación de este reglamento, por ser este organismo el rector de la política laboral en el país.

Por su parte, el Decreto núm. 326 (Reglamento del Código de Trabajo) en su capítulo XI "Seguridad y salud en el trabajo" establece el procedimiento para la investigación, registro e información de los incidentes y accidentes de trabajo y tal sentido se refiere a que el empleador está obligado a preservar las condiciones del lugar o puesto de trabajo donde se producen los daños, determinar las causas que lo originaron, los responsables y los daños a la salud de las personas, adoptar las medidas que eviten hechos similares, aplicar medidas disciplinarias, informar a la Oficina Nacional de Inspección del Trabajo, conservar el informe y registrar los incidentes y accidentes de trabajo a los efectos de la información a brindar.

Este breve análisis sobre la evolución y desarrollo de la seguridad y salud en el trabajo en el ámbito nacional, revela la necesidad de que las empresas y sus directivos específicamente se percaten que el cumplimiento de su objeto social o el de las normas jurídicas no son las únicas causas para determinar que una empresa es socialmente responsable, pues la seguridad y salud en el trabajo se ha convertido por 
derecho propio en otro de los parámetros esenciales para reconocerla como responsable socialmente; por tanto, por la novedad que reviste el tema, resalta la necesidad de su profundización como base importante para el perfeccionamiento de la práctica jurídica en el país, ante lo que se presenta comúnmente el reto de la formación de una cultura jurídica en torno a este particular, máxime cuando el factor humano es esencial en cualquier sistema de trabajo, por ello la gestión de los recursos humanos (GRH) ocupa, cada vez más, un lugar importante dentro de las estrategias de la organización.

Siguiendo la idea anteriormente planteada, es menester acotar que Cuba ha firmado diversos convenios de la OIT, que se hacen extensivos a todas las empresas; por ejemplo el Convenio núm. $155^{38}$ sobre seguridad y salud en el trabajo de 1981 (entró en vigor el 11 de agosto de 1983 y fue ratificado por Cuba el 7 de septiembre de 1982), cuyo principio fundamental es el establecimiento de una política nacional coherente en materia de SST y de protección al medio ambiente de trabajo, siendo aplicable a todas las ramas de la economía y a todos los trabajadores. También firmó el Convenio núm. $19^{39}$ sobre la igualdad de trato en cuanto a los accidentes de trabajo de 1925 (entró en vigor el 8 de septiembre de 1926 y fue ratificado por Cuba el 6 de agosto de 1928), el cual establece la igualdad de trato entre trabajadores extranjeros y cubanos en materia de indemnización de accidente de trabajo, o sea, que el Estado cubano tiene la responsabilidad de garantizar mediante la asignación y planificación, los recursos materiales y financieros necesarios para crear las condiciones adecuadas de SST.

EI SGSST va encaminado a garantizar las condiciones de seguridad y salud de los trabajadores(siendo el director de la empresa el máximo responsable de su elaboración, implementación, control y revisión), por lo que su alcance va más allá, actuando como factor de motivación y eficiencia de los trabajadores sobre la base de integrar

\footnotetext{
${ }^{38}$ Véase Viamontes Guilbeaux, Eulalia de la Caridad, Derecho laboral cubano. Teoría y legislación, La Habana, Félix Varela, t. I, 2005, p. 271.

${ }^{39}$ Idem, p. 265.
} 
sus principios y tareas a los sistemas de gestión y en general a las distintas actividades y funciones de la empresa, lo que incide en que ésta sea responsable socialmente, por lo que las malas condiciones de trabajo provocan lesiones a los trabajadores, pérdida de bienes materiales y deterioro del clima laboral, además de la poca productividad; por tanto, un eficiente SGSST es aquel donde exista una correcta armonía entre sus elementos configuradores.

\section{ELEMENTOS QUE CONFIGURAN LOS SISTEMAS DE GESTIÓN}

\section{DE LA SEGURIDAD Y LA SALUD EN EL TRABAJO}

Sentado previamente el papel de la seguridad ocupacional, laboral o del trabajo, cabe enfatizar que el empleador debe mostrar un liderazgo y compromiso firme respecto a las actividades de seguridad y salud laboral en la organización, así como adoptar las disposiciones necesarias para crear un SGSST, que incluya los siguientes elementos: definición de la política de seguridad de la empresa, organización de la seguridad, identificación y evaluación de riesgos y determinación de las causas de accidentes, programas de prevención y el control y ajuste de la seguridad, cada una de ellos cuenta con salidas importantes.

En este orden la Norma Cubana 18001 de $2005^{40}$ establece los elementos que deben conformar los SGSST implementados en nuestras empresas, en tal sentido refiere: política de la seguridad y salud en el trabajo, planificación, implementación y operación, verificación y acción correctiva y por último la revisión por la dirección, los que guardan una estrecha relación entre sí y por tal motivo una mala elaboración en uno de ellos afectaría de forma directa a los restantes y en consecuencia un mal diseño y aplicación del SGSST en la empresa; sus características principales se detallarán a continuación.

Con respecto a la definición de la política de seguridad de la empresa, constituye una necesidad de que los directivos conozcan los componentes de la seguridad de los cuales son responsables. Muchos de los dirigentes

\footnotetext{
${ }^{40}$. Norma Cubana NC 18001, 2005, Seguridad y Salud en el Trabajo - Sistema de Gestión de Seguridad y Salud en el Trabajo- Requisitos, Oficina Nacional de Normalización, edición de enero de 2005.
} 
aun cuando su formación es universitaria no poseen una cultura jurídica en cuanto a los temas relacionados con la SST, por lo que es uno de los principales problemas a resolver en este tópico y de los principales retos de aquellos que en la empresa tienen la función de asesorar en estos temas, pues en la medida en que el principal dirigente asuma esta responsabilidad y establezca una política adecuada a las necesidades y características de la organización, entonces será efectiva y tendrá éxito la labor de la SST.

La política de seguridad deberá trazarse y controlarse por el máximo órgano de la entidad, en este sentido nos referimos al Consejo de Dirección, por lo que debe estar en concordancia con los objetivos y proyecciones estratégicas de la organización; y su éxito será alcanzado siempre que se materialice en los siguientes aspectos: la elaboración de un compromiso u objetivos en materia de seguridad, la implicación y motivación de toda línea jerárquica, de modo que dichos objetivos se asuman por cada área y trabajador, el desarrollo de una cultura empresarial más amplia alrededor de estos temas, el tratamiento sistemático de los temas de la seguridad en los consejos de dirección, en el contexto de todos aquellos puntos que lo requieran, el recorrido periódico por los lugares de trabajo y la utilización sistemática por la empresa de los indicadores de seguridad como herramienta de dirección. ${ }^{41}$

La alta dirección debe definir una política de seguridad y salud en el trabajo de la organización, que establezca claramente los objetivos generales de esta materia y el compromiso de mejorar su desempeño. Dicha política debe: a) ser apropiada a la naturaleza y magnitud de los riesgos de SST de la organización; b) incluir el compromiso de la mejora continua; c) incluir el compromiso de cumplir con la legislación vigente aplicable sobre SST y con otros requisitos suscritos por la organización; $d$ ) estar documentada, implementada y ser mantenida; e) ser comunicada a todos los trabajadores con el propósito de que ellos conozcan cada una

\footnotetext{
${ }^{41}$ Torrens Álvarez, Odalys, La gestión de seguridad y salud en el trabajo en el marco de la gestión de los recursos humanos en la empresa, La Habana, Ministerio de Trabajo y Seguridad Social, 2003; Rodríguez Álvarez, Iraida, op. cit., p. 12.
} 
de sus obligaciones y responsabilidades individuales respecto al SST; $f$ ) estar a disposición de las partes interesadas; y $g$ ) ser revisada periódicamente para asegurar que siga siendo pertinente y apropiada para la organización.

Por su parte, la planificación de la seguridad en la empresa ha sido uno de los temas de más debate y de diversas tendencias. Desde este punto de vista, el juicio más generalizado versa en el sentido de que aquéllas deben de planificar la seguridad de modo que les permita materializar con efectividad su política y objetivos en este campo, a partir de la definición de su estructura y la organización funcional más conveniente; y a tales efectos se deben de precisar los siguientes aspectos: el directivo de la empresa que coordinará y controlará esta actividad, la existencia o no de un área especializada o de especialistas propios que desarrollen en la actividad la asesoría técnica en esta disciplina, su autoridad funcional y el nivel, así como el área de dirección a que quedarán adscriptos, la conveniencia o no de utilizar especialistas que atiendan más de una unidad de una misma entidad 0 , incluso, de asesorar esta labor empleando personal de instituciones especializadas y, por último, las funciones correspondientes a la seguridad, que deberán integrarse al contenido y responsabilidades de cada área y trabajador, según su actividad y esfera de competencia, incluyendo la autoridad de los mandos respecto de la seguridad e integrando a sus funciones las tareas que correspondan.

Según los profesores López Gandía y Blasco Lahoz, ${ }^{42}$ la seguridad laboral posee determinados perfiles o caracteres que han de tenerse en cuenta a la hora de diseñar el sistema de gestión de la seguridad y salud en el trabajo, en tal sentido se esbozan: es un deber de contenido amplio y genérico, pues abarca todos los aspectos relacionados con el trabajo que puedan afectar a la salud de los trabajadores y obliga a dictar cuantas medidas sean necesarias, es un deber de contenido dinámico y variable teniendo en cuenta los cambios de la técnica, de las condiciones de

\footnotetext{
42 Véase López Gandía, Juan y Blasco Lahoz, José Francisco, Curso de prevención de riesgos laborales, 5a. ed., Valencia, Tirant lo Blanch, 2003, p. 58.
} 
trabajo y de las circunstancias en que se ejecuta el trabajo y se traduce en una obligación de medianos resultados. Es una obligación de hacer por la que el empresario debe realizar una actividad preventiva de modo permanente para evitar que se produzcan daños, lo que se persigue no es meramente que se cumplan efectiva y realmente las medidas de seguridad previstas para evitar los peligros que la actividad laboral en cada caso pueda comportar, sino que se trata, en definitiva, de proteger la salud y vida de los trabajadores a través del cumplimiento de unas medidas concretas de seguridad y por ello no basta acreditar que existen o que han propuesto tales medidas de seguridad, sino que realmente se han cumplido.

La estructura organizativa que se adopte ha de permitir dar respuestas a los objetivos trazados, con la mayor agilidad posible, teniendo en cuenta los siguientes factores: niveles de riesgo presente (existencia de procesos de alto riesgo, puestos riesgosos), número de trabajadores, en particular los expuestos a riesgo, características organizativas (carácter abierto o cerrado de la entidad y turnos de trabajo), dispersión de las unidades organizativas en cuanto a su cantidad y distribución y la integración de la seguridad en los contenidos y responsabilidades. Por lo que es evidente que la incorporación de la SST a cada una de las áreas de gestión de la empresa tienen relación directa con las funciones ejercidas por el jefe directo; por lo que su papel es fundamental en la instrucción y adiestramiento del personal, el control o autoinspección de la seguridad, establecimiento de determinadas medidas y acciones preventivas y, por supuesto, en la utilización de formas participativas de dirección que resultan importantes en la GSST de los trabajadores.

La implementación, como otro de los elementos del SGSST, acota que se debe definir, documentar y comunicar las funciones, responsabilidades y autoridad del personal que dirige, ejecuta y verifica actividades que tengan efecto sobre los riesgos para la seguridad y salud en el trabajo, de las actividades, instalaciones y procesos de la organización, para facilitar una gestión de SST eficaz. La responsabilidad final por la SST radica en la alta dirección, por lo que la organización debe designar a un representante dentro de ella (por ejemplo, en una organización, un 
miembro del Consejo de Dirección) con la responsabilidad y autoridad particular de asegurar que el sistema de gestión de la SST esté implementado adecuadamente y que se desempeña de acuerdo con los requisitos en todos los lugares y esferas de operación dentro de la organización. La dirección debe proporcionar los recursos esenciales para implementar, controlar y mejorar el sistema de gestión de la SST.

En este orden la organización debe identificar y determinar aquellas operaciones y actividades asociadas a los riesgos evaluados, donde sea necesario aplicar medidas de control. La organización debe planificar estas actividades, incluyendo su seguimiento, para asegurar que se efectúen bajo condiciones especificadas, mediante: a) el establecimiento y seguimiento de procedimientos documentados para cubrir situaciones en las que su ausencia podría llevar a desviarse de la política y objetivos de SST; b) el establecimiento de los criterios operacionales en los procedimientos; c) el establecimiento y seguimiento de procedimientos relacionados con los riesgos identificados con respecto a bienes, equipos y servicios adquiridos o usados por la organización y la comunicación de los procedimientos y requisitos pertinentes a los proveedores $y$ contratistas, y $d$ ) el establecimiento y seguimiento de procedimientos para el diseño del lugar de trabajo, procesos, instalaciones, maquinaria, procedimientos operativos y organización del trabajo, incluyendo su adaptación a las capacidades humanas, para eliminar o disminuir los riesgos en su fuente.

Por su parte, la identificación y evaluación de los riesgos o conocida como el proceso de verificación y acción correctiva, constituye el punto de partida para definir posteriores acciones en materia de seguridad, que abarcan soluciones técnicas y organizativas, incluidos, entre otros, el establecimiento de medidas de gestión más adecuadas en lo que conciernen a la instrucción y otras acciones formativas, la utilización de equipos de protección personal, lo requisitos para la selección de los trabajadores en aquellos puestos de carácter riesgoso así como la estimulación moral y material de los trabajadores, etcétera. De aquí se deriva la necesidad de identificar todos los factores causales o los riesgos que hayan provocado accidentes, incidentes o representen solamente la 
posibilidad de ocurrencia de tales hechos.

La organización debe establecer y mantener procedimientos para definir la responsabilidad y autoridad para el tratamiento e investigación de accidentes e incidentes ocurridos durante o con motivo del trabajo; la aplicación de acciones para mitigar cualquier consecuencia derivada de estos accidentes e incidentes; la iniciación y finalización de las acciones preventivas y correctivas; así como la confirmación de la eficacia de las acciones preventivas y correctivas tomadas. Estos procedimientos requieren que, previo a su implantación, todas las acciones preventivas y correctivas propuestas deban ser revisadas mediante el proceso de evaluación de riesgo. Cualquiera de estas acciones llevadas a cabo para eliminar las causas de estos accidentes e incidentes, deben ser apropiadas a la magnitud de los problemas y acorde con los riesgos para la SST encontrados en la empresa.

En cambio, los programas de prevención -expresión de las acciones que se deben de realizar - deben de incluir los elementos que a continuación se relacionan: medidas para la mejora continua de las condiciones de trabajo, como inversiones, remodelaciones, mantenimiento, etcétera, programa de capacitación de los dirigentes y trabajadores, recursos financieros y organizativos necesarios a estos fines, servicios y vigilancia de la salud de los obreros, equipos de protección personal y protección contra incendios y el trabajo con las comisiones de la seguridad y salud en el trabajo y el movimiento de áreas protegidas.

Con respecto, a esto López Gandía y Blasco Lahoz, ${ }^{43}$ en su obra, hacen alusión a algunas de las motivaciones para la prevención de riesgos laborales y tutela de la salud laboral; y en este orden refieren que esquemáticamente pueden señalarse los factores que se relacionan a continuación: las reivindicaciones históricas de los trabajadores a favor de la mejora de las condiciones de vida y trabajo y de alcanzar un nivel general de bienestar, la configuración de un deber empresarial de seguridad (deuda de seguridad) derivado de la existencia de un contrato de trabajo con sus notas de ajenidad y dependencia del que derivan

\footnotetext{
${ }^{43}$.Ibidem, p. 17.
} 
ciertas consecuencias jurídicas y la inversión en seguridad y salud laboral como medio indispensable para avanzar en otros objetivos y programas de mejora de la empresa. De igual manera refieren que los servicios de prevención se componen por el conjunto de medidas materiales y humanos, contando con varias etapas.

En este mismo sentido los profesores antes mencionados abordan sobre las funciones del servicio de prevención; sobre este particular exponen en su libro que las tres funciones principales que deben cumplir son: asesoramiento y apoyo, estar en función de los tipos de riesgo y la vigilancia de la salud de los trabajadores, detallando en cada una de estas funciones cuáles son las acciones que se deben de desarrollar para el logro de los objetivos de dicho servicio de prevención.

Como último de los elementos del SGSST, se encuentra la revisión por la dirección, en ella se expresa que la máxima dirección de la empresa debe de acuerdo a los periodos que determine, revisar el sistema de gestión de SST, para asegurar su continua aptitud, adecuación y eficacia. En este proceso de revisión debe de reunir toda la información necesaria para que la dirección pueda efectuar esta evaluación, por lo que debe ser documentada. La revisión por la dirección debe considerar la eventual necesidad de cambios en la política, los objetivos y otros elementos del sistema de gestión de SST en función de los resultados de auditorías, de cambios en las circunstancias y del compromiso de mejora continua.

La eficacia de las acciones de seguridad requiere un adecuado control de esa actividad en la empresa, mediante indicadores apropiados y la comprobación de los resultados obtenidos con los objetivos, las normas y otros parámetros de referencia, tantos internos como externos, con vistas a establecer las medidas correctivas que resulten oportunas. El sistema de control que se establezca en la empresa debe garantizar la actuación preventiva y el control de las acciones referidas a hechos ocurridos, tiene su concreción con la inspección sistemática, muestreos ambientales, evaluación del comportamiento de los trabajadores, el análisis de actitudes, la evaluación de la salud, el estudio de la documentación y los registros de accidentes, incidentes, enfermedades y recomendaciones derivadas de inspecciones realizadas; cuestión que permite evaluar 
efectividad, eficiencia y eficacia.

Un punto muy polémico y complejo dentro de las empresas es lo concerniente a la asignación de los recursos financieros para la ejecución de las acciones, en este sentido, aquéllas deben trazar la estrategia adecuada para garantizar la asignación más efectiva y velar por su cumplimiento. Siguiendo el fundamento de esta línea argumental, las profesoras Torrens Álvarez y Rodríguez González ${ }^{44}$ plantean que los programas de prevención pueden abarcar además de los particulares enunciados, los siguientes aspectos: cumplimiento de medidas dictadas por inspecciones (en este orden comprende tanto las inspecciones estatales como la inspección sindical), formas de estimulación y reconocimientos por el cumplimiento en SST, acciones de comunicación y divulgación (en este apartado juega un papel importante el logro de una cultura jurídica empresarial, tanto para los trabajadores como para los directivos en sentido general, a partir de darles a conocer las diferentes normas que en materia de SST rigen en nuestro ordenamiento jurídico, siendo los principales exponentes en este actuar, el asesor jurídico como el técnico en seguridad y salud de la empresa), las evaluaciones de riesgo así como otros elementos que se consideren necesarios incluir en el programa de prevención teniendo en cuenta las particularidades de las empresas.

En este sentido los trabajadores desempeñan un papel importante en el control de las acciones en materia de SST, por lo que los sindicatos contribuyen de manera eficaz al desarrollo de esta labor a través de las autoinspecciones sindicales (aspecto casi nulo en nuestras empresas), la selección y el adiestramiento de los inspectores sociales y el movimiento de áreas protegidas, entre otras, que en consecuencia han de recibir el apoyo más decidido por parte de la administración; por lo tanto, debe de concederse especial atención a la inclusión en el Convenio Colectivo de Trabajo de todas las acciones que garanticen la seguridad y el mejoramiento de las condiciones de trabajo. La participación real y efectiva de los trabajadores no es en la forma que en muchos de los casos

\footnotetext{
${ }^{44}$ Véase Torrens Álvarez y Rodríguez González, op. cit., p. 17.
} 
ocurre en las empresas y se limita a una fase en particular, ya sea inicial o última de información para la implementación de determinadas acciones, sino que se trata de la utilización de la calificación alcanzada por los trabajadores en la evaluación de los problemas y en alternativas de solución. Este es un desafío que debe enfrentar la dirección de las organizaciones aún más cuando nuestro país está llevando en estos momentos una actualización de nuestro proyecto social y económico.

Con respecto a los elementos que conforman los SGSST, es importante señalar que en nuestro ordenamiento jurídico laboral cubano (OJLC) no aparecen regulados de una manera organizada y coherente en un artículo específico; por el contrario, se encuentran dispersos por todo el articulado que componen el capítulo XI del Código de Trabajo en relación con el capítulo XI de su reglamento referentes ambos a la seguridad y salud en el trabajo, tema con el que no estamos de acuerdo, pues consideramos que estos elementos deben ser regulados en un artículo específico de nuestro código laboral, máxime cuando constituyen los pilares fundamentales en los que se sustenta el SGSST de cualquier empresa para lograr su eficaz resultado - la seguridad y salud del trabajador_, esgrimiendo además que el Código de Trabajo es la norma general que regula todo lo concerniente a las relaciones que se fomentan en ese ámbito siendo aplicable a todos los empleadores radicados en el territorio nacional así como a las personas nacionales o extranjeras con residencia permanente en el país.

Por otra parte, si se realiza un estudio pormenorizado de las cláusulas fundamentales de los contratos de trabajo formalizados en estos momentos en nuestras entidades, podemos percatarnos que con respecto a los elementos de los SGSST no hay reconocimiento alguno, dichas cláusulas sólo se limitan a establecer que tanto el trabajador como la administración están obligados a cumplir con las normas de seguridad y salud en el trabajo, tal redacción permite realizar la siguiente interrogantes ¿cuáles normas de seguridad y salud en el trabajo están obligados a cumplir? Evidentemente las normas a obedecer son las que están en estrecha relación con la actividad laboral o el cargo que desempeñan los sujetos de la relación jurídica laboral anteriormente 
mencionados, siendo válido aclarar que no todos los trabajadores están sujetos a las mismas condiciones de SST aun cuando ejecutan su labor en la misma entidad, razón por la cual considero que cada contrato de trabajo debe de contener las condiciones específicas en cuanto a la materia abordada y no ser de carácter general como se ha venido realizando de forma tradicional en nuestras entidades.

Otro aspecto importante a señalar en torno a la SST, que por lo general sucede en gran parte de nuestras empresas, es que en ocasiones aquellos que más lejos están de los riesgos, son los realizadores de las actividades correspondientes a los niveles de política y evaluación, esto trae como consecuencia la presentación a los trabajadores de procedimientos y medidas que pueden o no tener relación directa con su trabajo y deben cumplir bajo reglamentación en la mayoría de los casos, siendo tratados a veces como un objeto más de dirección dentro de las actividades de seguridad y no como los sujetos protagonistas de los cambios en las empresas, entonces ¿serían responsables socialmente las empresas donde sucede estas situaciones?

En este sentido, resulta cuestionable su responsabilidad social, pues por un lado no se concibe que las actividades correspondientes a los niveles de política y evaluación sean elaboradas por aquellas personas que no están en contacto directo con los riesgos laborales, debido a que esto provocaría la no pertinencia de esta política a las condiciones existentes en la entidad $y$, por el otro lado, no se concibe que el trabajador no tenga protagonismo en los cambios de la empresa y en particular a lo relacionado con la SST, si precisamente la RSE lo que busca es la participación de todos los actores de la empresa en el desarrollo de la misma como en el mejoramiento del entorno donde está situada, lo que tributaría al logro del bienestar de la sociedad.

En efecto, la integración de la SST en la empresa supone que la toma de cualquier decisión o el desarrollo de cualquier acción debe analizarse no sólo desde sus consecuencias productivas, sino también desde las preventivas; de esta manera, un proceso de integración de la SST en la actividad empresarial implica que los requisitos preventivos aplicados no sólo sean los estrictamente productivos, sino todos los exigibles en el 
puesto de trabajo en relación con el objeto social de la empresa. Desde este punto de vista, no existen varios procesos de gestión por separados, dígase una gestión de la parte productiva y otra de la parte preventiva, sino que cualquier actividad dentro de la empresa es objeto de una única gestión, por lo que la empresa, a partir de los conocimientos adquiridos en materia preventiva, debe valorar y posteriormente ejecutar la acción en torno a la SST, no obstante la praxis jurídica nos ha demostrado que esto no se ha llevado a cabo con la intensidad que sería deseable y ello básicamente por la ausencia de una cultura preventiva tanto en la empresa como en los trabajadores y en la sociedad en sentido general.

Por tanto, una empresa socialmente responsable es la que logra la total integración de la SST en la empresa, integración que debe realizarse de forma variable atendiendo a las responsabilidades de cada uno de los directivos que tienen responsabilidad en cada una de las áreas de la empresa. Será una integración con diferentes variables en la que su intensidad decrecerá a medida que se asciende en la escala jerárquica, de esta manera el trabajador se corresponsabiliza en la gestión de la SST, en relación con la implementación y control del SGSST, aunque es válido aclarar que no todas las actividades productivas de la empresa requieren del mismo nivel de integración; es precisamente ahí, a nuestro juicio, donde radica su responsabilidad social, en la asunción de medidas de SST en beneficio de su fuerza de trabajo.

A criterio de este investigador, la SST es efectiva en la medida en que cumpla con los objetivos que se propone; es eficiente cuando los recursos que emplee se reviertan en la eliminación de riesgos y el mejoramiento de las condiciones de trabajo y es eficaz cuando logra satisfacer las expectativas de los trabajadores y de la organización incluyendo los elementos referidos a la productividad y la calidad; por tal motivo, un adecuado modelo de GSST, es aquel que garantice una armónica relación entre los ejes fundamentales del proceso: dirigentes-trabajadores, administración-sindicato, capaz de facilitar la ejecución del trabajo de manera segura, a través de la prevención de accidentes de trabajo y enfermedades profesionales, incidentes en el medio ambiente del trabajo y con esto contribuir a la eliminación de las insuficiencias que puedan 
presentar los SGSST en nuestras empresas, cuestión que constituye una deuda en estos momentos en el sector empresarial.

\section{PRINCIPALES INSUFICIENCIAS DE LOS SISTEMAS DE GESTIÓN DE LA SEGURIDAD Y LA SALUD EN EL TRABAJO}

Las insuficiencias en la concepción de los sistemas de gestión de la seguridad y salud en el trabajo no sólo se encuentran en el orden normativo, sino también en la interpretación y aplicación de las normas jurídicas que regulan tal institución. En todo este tránsito se originaron situaciones que ocasionaron problemas en la praxis; para delimitarlo, este autor se han planteado realizar un diagnóstico que, a partir del estudio teórico doctrinal realizado, permita precisar las principales insuficiencias de los SGSST en las empresas seleccionadas y su incidencia en la aplicación de la responsabilidad social empresarial.

La selección de la muestra se realizó bajo los siguientes criterios: un muestreo a los manuales de la seguridad y salud del trabajo, planes de prevención de riesgos y los convenios colectivos de trabajo de las empresas Pasteurizadora El Alba, UEB El Cárnico, Combinado Lácteo, La Hacienda y la UEB productora de medicamentos líquidos del Laboratorio Oriente, todas pertenecientes al municipio Bayamo. Estas empresas fueron escogidas por la importancia económica que tienen en el municipio, por ser empresas en perfeccionamiento empresarial y por la exposición de los trabajadores a determinados riesgos laborales debido a la propia actividad laboral que en estos lugares se realizan. A tales efectos se utilizó la técnica de revisión de documentos, específicamente los mencionados al inicio, así como un muestreo a los actores involucrados en los procesos productivo y de dirección, mediante la utilización de la técnica de encuesta.

Se analizaron las anteriores unidades de muestra y los criterios de análisis abordados pudieron demostrar el carácter integrador que tiene la investigación cualitativa, enfocado desde un aspecto esencial: las insuficiencias en los sistemas de gestión de la seguridad y salud en el trabajo incidente en la adecuada aplicación de la responsabilidad social empresarial. En este aspecto se tuvo en cuenta la revisión de los SGSST para establecer los nexos con los otros elementos, cítese: previsión de los 
riesgos, participación de los trabajadores en las actividades relacionadas con la SST, la cultura empresarial, lo que permitió identificar lo complejo que resulta su elaboración y aplicación.

En tal sentido, la revisión de los sistemas de gestión de la seguridad y salud en el trabajo arrojaron las siguientes dificultades:

- Se pudo constatar que es insuficiente el control sistemático de los jefes de las entidades a las actividades previstas en los SGSST. El hecho de contar con una normativa específica en materia laboral que elimina la dispersión jurídica con respecto a este particular, no es suficiente para argumentar que esté en consonancia con las actuales condiciones de seguridad y salud presentes en las empresas mencionadas, pues el principal problema radica en que los máximos jefes de estas entidades todavía delegan la función de controlar los SGSST en los especialistas de la seguridad y salud en el trabajo presentes en las empresas, no concibiendo que dicho control es una responsabilidad inherente tanto al empresario como a los directores de las empresas. Tal cuestión se evidencia a partir de una interpretación extensiva de lo regulado en nuestro Código de Trabajo en los preceptos legales del 134 al 137 en relación con lo estipulado en su reglamento en los artículos 151 al 153.

- La no previsión de todos los riesgos incidentes en el ámbito laboral constituye todavía en las empresas muestreadas una falta de pericia, los jefes de las entidades olvidan la importancia que reviste la identificación de todos los riesgos que pueden afectar la seguridad y la salud de los trabajadores en la realización de su actividad laboral, cuestión refrendada en nuestro Código de Trabajo en los artículos 134, 135 y 137 en relación con el artículo 151 de su reglamento. La correcta previsión de todos los riesgos servirá para modificar y organizar adecuadamente las actividades preventivas que corresponden así como para elaborar el programa de prevención. Para una mejor eficacia de este proceso podrán adoptarse las acciones siguientes: observación del lugar de trabajo, evaluando sus vías de acceso, la seguridad de sus maquinarias, etcétera; controlar las tareas realizadas, así como las operaciones y procedimientos llevados a cabo para lograr la eficacia del mismo; un estudio del régimen de trabajo y la carga del 
mismo, organizando la realización del proceso productivo por turnos de trabajo (siempre que la actividad laboral y la condiciones de la empresa lo permitan) que posibiliten un horario de trabajo en proporción al descanso y por último, prever los posibles accidentes, incidentes o averías así como las acciones de respuestas que deben adoptar los trabajadores para reducir las consecuencias y el riesgo ocasionado.

— La falta de cultura empresarial es otra de las cuestiones que afectan la eficacia de los SGSST, en este sentido se evidencia que el plan de capacitación y superación tanto de los trabajadores como de los dirigentes en torno a esta temática, no responden en la mayoría de los casos a las necesidades particulares de estos destinatarios o, en el mejor de los casos, no están en correspondencia con la circunstancias existentes en las entidades como en la de los propios puestos de trabajo.

- Deficiente papel protagónico de la organización sindical en los SGSST; en este orden, el sindicato debe estar presente de forma prioritaria en cada uno de los eslabones de la seguridad y salud en los centros; tanto en el levantamiento de riesgos como en la determinación de los medios de protección necesarios. Tal cuestión queda reafirmada en nuestro Código de Trabajo a partir de lo preceptuado en el artículo 15 incisos a y d concerniente a las facultades de la organización sindical.

- No existe una sistematicidad de los principios de la seguridad y salud en el trabajo en nuestro OJLC, pues no son reconocidos como tales, sino que se encuentran recogidos dentro de las obligaciones y derechos de las partes, artículos 134, 135, 137 y 138 del CT en relación con los artículos 151 y 153 del reglamento del CT.

El examen de la muestra nos permite reafirmar, que a pesar de la existencia de nuestro Código de Trabajo, en el cual se dan por sentadas las bases generales de la Seguridad y Salud en el Trabajo, todavía persisten insuficiencias en los SGSST, que transitan desde la elaboración, control, revisión hasta el proceso de evaluación de los mismos, lo que evidencia la necesidad de enaltecer el papel preponderante que tiene tal institución laboral, máxime cuando los trabajadores constituyen el 
elemento esencial dentro de una empresa, sin los cuales sería imposible lograr el cumplimiento de su objeto social.

A estas valoraciones se une también la deuda que tenemos los juristas con respecto al estudio de esta problemática, pues consideramos que la misma no constituye tema fundamental para llevar a cabo la realización de investigaciones desde esta parcela del conocimiento, cuestión ésta errónea, pues hoy la praxis jurídica nos ha demostrado que no sólo basta con el estudio de las normas jurídicas laborales con la finalidad de plantear si son eficaces o no, a ello se le añade la necesidad de enfocar que como parte de ese centro y destinatario de estas normas laborales se encuentra el trabajador, en cuanto ser biosicosocial, por ende, siempre expuesto a riesgos y por tanto necesita que en el medio donde se desenvuelve estén creadas las condiciones seguras para el pleno desarrollo de sus capacidades intelectuales y físicas.

Para la realización del muestreo a los actores involucrados en el proceso se aplicó la encuesta en cada una de la entidades seleccionadas, a tales efectos fueron encuestados 500 trabajadores, de ellos 200 operarios (40\%), 150 técnicos (30\%), 50 administrativos (10\%), 50 de servicios (10\%) y 50 cuadros ejecutivos (10\%). A partir de la cual nos permitió obtener los juicios de valor de cada uno de estos trabajadores, con vista a la propuesta de los presupuestos teóricos que permitan una mejor elaboración de los SGSST y con esto a la adecuada aplicación de la responsabilidad social empresarial desde el ámbito laboral en nuestras empresas.

La encuesta arrojó los siguientes resultados:

- Con respecto al conocimiento sobre la responsabilidad social empresarial como herramienta de gestión que las empresas aplican para alcanzar un mejor desempeño, protección del medio ambiente y contribuir al desarrollo del bienestar social, que posibilita mayores niveles de Seguridad y Salud en el Trabajo; 360 trabajadores (72\%) plantearon que no tenían conocimiento del tema; 140 (28\%) trabajadores esgrimieron que conocían sobre el tema. Este primer resultado nos evidencia que en nuestro país a pesar de tener condiciones factibles para implementar la RSE debido al sistema 
imperante, todavía son incipientes los estudios sobre dicha categoría, por lo que nos queda el reto de seguir haciendo énfasis en los foros científicos, la necesidad de implementar la RSE en nuestras empresas.

- En torno a la evidencia de la relación de los SGSST y la RSE en las empresas seleccionadas, lo que tributa a la prevención de los accidentes de trabajo y de las enfermedades profesionales, 350 trabajadores (70\%) plantearon que en sus empresas sí se manifiesta tal relación y 150 (30\%) hicieron referencia de que no hay relación entre Ios SGSST y la RSE. Para una mejor comprensión de este apartado, los 350 trabajadores que plantearon de que en sus empresas sí existía relación entre los SGSST y la RSE, tuvieron que realizar una valoración de la implementación de dichos sistemas en sus entidades, a partir de los aspectos que se relacionan a continuación:

- La política de seguridad y salud establecida en la entidad estaba en correspondencia con las necesidades y características de la organización, de ellos 200 trabajadores (40\%) respondieron que sí, 85 (17\%) respondieron que no y 65 (13\%) respondieron que en algunos aspectos era que guardaban relación, específicamente lo relacionado con los riesgos laborales.

- Con respecto a si se utilizaba de manera sistemática por la empresa los indicadores de seguridad y salud en el trabajo como una herramienta de dirección, 120 trabajadores (24\%) plantearon que sí, 180 (36\%) respondieron que no y 50 (10\%) abordaron que en algunas ocasiones se utilizaban.

- En cuanto al conocimiento de las normas jurídicas que regulan la SGSST en la empresa, 200 trabajadores (40\%) plantearon que tienen poco conocimiento de estas normas, 100 (20\%) refirieron a que tenían un conocimiento amplio de las normas y 50 (10\%) plantearon que no tenían ningún conocimiento

- Lo referente a la participación de los trabajadores en las actividades previstas en el SGSST, 30 trabajadores (6\%) plantearon como buena la participación, 70 (14\%) refirieron a que es regular la participación, 100 (20\%) aludieron de que es mala la participación y 150 (30\%) esbozaron 
de que no participan.

- La opinión de los encuestados con respecto a que si los SGSST de sus empresas estaban en correspondencia con las normas vigentes en esta materia, se comportó de la forma siguiente: 200 (40\%) plantearon que sí se corresponde, 85 (17\%) esgrimieron de que no se corresponden y 65 (13\%) plantearon de que no sabían si existía correspondencia o no.

- Con respecto a la participación del sindicato en cada una de las actividades planificadas en el SGSST de la empresa, 150 trabajadores (30\%) plantearon que sí y sus respuestas versaron fundamentalmente en lo concerniente a la elaboración sin tener una participación activa en las demás etapas de los SGSST y 200 (40\%) manifestaron que el sindicato no participaba en las actividades planificadas en el SGSST de la empresa.

- Referente a la cultura empresarial en torno a este tema, 55 trabajadores (11\%) manifestaron que en la empresa existe una amplia cultura sobre el tema, 200 (40\%) plantearon que hay poca cultura y 95 (representan un 19\%) que no existe cultura sobre dicho tema en la empresa.

— En relación con que si el SGSST implementado, recoge todos los riesgos existentes en la empresa y que puede afectar a su seguridad y salud, 100 trabajadores (20\%) respondieron que sí, 200 (40\%) refirieron que no y 50 (10\%) aludieron a que no sabían lo que son los riesgos en el ámbito laboral.

En cuanto a los 150 trabajadores que manifestaron que no existe relación entre los SGSST y la RSE en sus empresas, sustentaron sus criterios en los siguientes aspectos previstos en la pregunta 2.2 de la encuesta:

- Con respecto a que la política de seguridad y salud en el trabajo no está en correspondencia con las necesidades y características de la organización, en este sentido 95 trabajadores (19\%) coinciden con tal planteamiento.

— En relación a que si no existe el compromiso por parte de los directivos responsables en cada uno de los componentes de la seguridad y salud 
en el trabajo; 90 trabajadores (18\%) manifestaron su concordancia con este acápite.

— En torno al deficiente conocimiento con respecto a las normas jurídicas vigentes en materia de seguridad y salud en el trabajo; 95 trabajadores (19\%) plantearon que no tienen conocimiento de estas normas y que en la entidad no se han realizado actividades encaminadas al conocimiento de estas normas jurídicas.

- Con respecto a la participación activa de los trabajadores en la implementación de los SGSST, 80 trabajadores (16\%) esgrimieron de que no hay una activa participación de los trabajadores en la implementación de los SGSST así como en las demás fases de estos sistemas, dígase: elaboración, control y evaluación. Por lo general, lo que sucede en la entidad es que los trabajadores ven y saben de los SGSST cuando ya están implementados y no le dan la oportunidad de plantear sus criterios.

- En otro orden, 80 trabajadores (16\%) manifestaron que los SGSST no abarcan todos los riesgos existentes en la empresa, lo que incide en la seguridad y salud en el trabajo. A esto se une de que muchos de estos trabajadores no saben los riesgos laborales a los cuales están expuestos en el cumplimiento de su actividad laboral y que no todas las administraciones de estas entidades han realizado espacios para fomentar la cultura jurídica de los trabajadores en torno a esta temática.

Por otro lado, en relación con las sugerencias que recomendarían los trabajadores para el perfeccionamiento de los SGSST, giraron en torno a las siguientes cuestiones: mayor participación de los trabajadores en las fases de los SGSST, dígase desde la elaboración hasta la verificación del mismo; mayor pertinencia de los SGSST con las condiciones actuales de las empresas; la necesidad de que los SGSST recojan todos los riesgos existentes en las empresas así como mayor participación de las organizaciones sindicales en cada una de las actividades planificadas en Ios SGSSTT.

Las insuficiencias en los SGSST ya expuestas, se sustentaron a partir de 
las encuestas aplicadas a los trabajadores en cada una de las entidades tomadas como muestra, lo que permitió evaluar el estado de la ciencia en el tema, la relación entre sus elementos así como la correspondencia entre la historia del mismo y la realidad existente en el contexto de las empresas. A partir de tal argumento, nos permitió avanzar en la configuración de los presupuestos teóricos que permitan su perfeccionamiento y la adecuada aplicación de la responsabilidad social empresarial en el ordenamiento jurídico cubano, contribuyendo a una mayor protección de la fuerza de trabajo.

\section{PRESUPUESTOS TEÓRICOS PARA EL PERFECCIONAMIENTO DE LOS SISTEMAS DE GESTIÓN DE LA SEGURIDAD Y SALUDEN EL TRABAJO}

A partir del diagnóstico realizado, hay claridad de que persisten insuficiencias en la concepción de los SGSST en las empresas, que transitan desde su elaboración hasta su implementación, cuestión avalada a partir de la encuesta aplicada en cada una de las empresas seleccionadas como muestra, siendo encuestados un total de 500 trabajadores, así como el análisis de las factores endógenos y exógenos que inciden en la implementación de dichos sistemas, a esto se une la carencia de presupuestos teóricos en nuestro ordenamiento jurídico que permitan la coherente concepción de estos sistemas. Estos presupuestos teóricos constituyen reglas de naturaleza doctrinal, que orientan las normas de un país para el logro de los fines que persiguen los SGSST en una empresa, es decir, la protección y seguridad de quienes brindan su fuerza de trabajo, en función de los intereses económicos, políticos y sociales del Estado.

Por tanto, son propuestos por este investigador un conjunto de supuestos teóricos que podrán ser tenidos en cuenta para perfeccionar estos sistemas en las empresas del municipio. En tal caso, es de entenderse como presupuestos que permitan la sistematización en relación con esta institución estudiada, su conceptualización y su regulación en las normas jurídicas que conforman el OJLC. Siendo los siguientes presupuestos a tenerse en cuenta:

\section{Perfeccionamiento de la regulación y aplicación de los principios}




\section{de la seguridad y salud en el trabajo en el OJLC}

Los principios en cualquier rama del derecho, constituyen los fundamentos en los que se sustentan así como permiten en el desarrollo de cada una de las instituciones objeto de estudio en cada una de estas ramas. En este sentido, Arturo de Diego ${ }^{45}$ plantea que se le denominan principios a las reglas o pautas inmutables que rigen la materia y que permiten preservar la unidad sistemática y orientar al intérprete como al legislador dentro de la rama específica.

Por su parte, Arce y Flores-Valdez ${ }^{46}$ plantean que los principios sirven de centro o referencia a la regulación de una parte del derecho o de una determinada institución jurídica, participan, en cuanto desarrollo de los principios generales del derecho y respecto del sector o institución en que se enmarcan, de una virtualidad mediata fundamentadora, orientativa, informadora y crítica.

En consonancia con esto, la profesora Viamonte Guilbeaux ${ }^{47}$ refiere que el concepto actual de principios del derecho laboral cubano, tal y como lo establece el Código de Trabajo, es la traslación de los derechos constitucionales a la dimensión del derecho laboral, de manera que no constituyen vías rectoras o lineamientos para proyectar esta rama del derecho, sino una relación de derechos que deben ser garantizados; argumentando además, que nuestro derecho laboral cubano debe transitar hacia un estadio de perfeccionar y lograr sus propios principios jurídicos sin confundirlos con otra institución jurídica bien definida, como son los derechos constitucionales.

Sin embargo, todavía en el OJLC sigue siendo una asignatura pendiente la regulación de los principios generales del derecho laboral y en particular los de la seguridad y salud en el trabajo, por ende, la necesidad de un desarrollo dogmático más amplio y del perfeccionamiento de su

\footnotetext{
${ }^{45}$ Véase Arturo de Diego, Julián, Manual de derecho del trabajo y de la seguridad social, $5 a$. ed., Buenos Aires, Lexis-Nexis/Abeledo-Perrot, 2002.

${ }^{46}$ Cfr. Podetti, Humberto A., Instituciones de derecho del trabajo y de la seguridad social, México, UNAM, Instituto de Investigaciones Jurídicas, 1997, cap. 8, p. 139.

${ }^{47}$ Viamontes Guilbeaux, Eulalia de la Caridad, Derecho laboral..., cit., pp. 53-57.
} 
regulación, permitirá su reconocimiento y respeto, como contribución a su correcta interpretación y aplicación en el ámbito laboral. De igual manera se reitera la necesidad de la regulación de estos principios en el texto constitucional, como los fundamentos básicos para ulteriores normativas, por tanto, a tales efectos, debe de existir un mayor vínculo entre los estudios constitucionales y laborales, específicamente en cuanto al perfeccionamiento de las garantías materiales del derecho a la seguridad y salud en el trabajo, pues no basta con tener normas jurídicas si no tenemos desarrollado toda una doctrina en cuanto a esta temática.

Se evidencia en el OJLC la presencia de algunos de los principios de la SST, no con una correcta técnica jurídica, incidente en no contextualizarlos como principios, lo que conlleva a una incorrecta interpretación y aplicación de los mismos; por lo que se hace necesaria la utilización de una correcta técnica de redacción jurídica a la hora de la elaboración de nuestras normas, unido a los criterios doctrinales consolidados y atemperados a los sujetos de la realidad social destinarios de los mismos, lo que permitirá la contextualización socioeconómica y el enfoque interdisciplinario de estos principios en el OJLC.

\section{Desarrollo de la cultura jurídica en materia}

\section{de seguridad y salud en el trabajo}

La cultura en materia de seguridad y salud en el trabajo constituye, dentro de las representaciones sociales, uno de los campos pocos explorados por las ciencias sociales y específicamente por las ciencias jurídicas. A pesar de ello existen pronunciamientos sobre la necesidad de tener en cuenta como elemento fundamental en el proceso productivo la SST, con el objetivo de lograr la concientización sobre esta temática, tanto a los empleadores como a los empleados o trabajadores.

No basta con tener normas de buena calidad, con elaborar e implementar los SGSST, con detectar los riesgos laborales a los que están expuestos los trabajadores en las empresas, con desarrollar la producción científica en esta materia, si a ello no se une la divulgación de todas estas acciones en la comunidad jurídica y en la sociedad en general; en particular la participación activa, efectiva y real de los sujetos protagonistas y destinarios de este proceso: los trabajadores, sin los 
cuales sería imposible llevar a cabo esta ardua faena.

En este aspecto, Torrens Álvarez ${ }^{48}$ refiere la importancia que tiene la capacitación tanto de los trabajadores como de los jefes directos en aras de disminuir los accidentes de trabajo, así como la necesidad de que el especialista en esta materia dentro de la empresa deberá estar preparado para enfrentarla y exigir desde su conocimiento, la utilización de los medios de protección, unido al papel protagónico de los jefes de las empresas como máximos responsables de exigir la disciplina. Por tanto, la preparación de los actores involucrados en los procesos que se generan en las empresas, ha de ser una de las actividades más importantes en la prevención de accidentes de trabajo, que comienza por la instrucción inicial impartida a todo el personal de nuevo ingreso, en dependencia de la forma de iniciar su relación jurídica laboral y persigue con la certificación y la ejecución de talleres y otras actividades.

El factor humano debe ser lo primordial adentro de una empresa, por eso la identificación de los riesgos en todos los puestos de trabajo constituye la base para la realización de un efectivo plan de prevención de riesgos en la empresas, en relación con el compromiso de todos los directivos y trabajadores de laborar con seguridad y evitar afectaciones a las personas, las instalaciones y al medio ambiente.

En consonancia con lo expresado, el profesor Capella ${ }^{49}$ plantea que los Estados tienen a su cargo la tutela administrativa de estas cuestiones, realizada a través de funcionarios inspectores y que son infinitos los aspectos de la actividad productiva que están estrictamente reglamentados desde el punto de vista de la higiene y la seguridad en cada una de las ramas de producción. Esta tutela administrativa, desde mi opinión, no ha generado cultura jurídica acerca de los derechos en materia de seguridad y salud de trabajo entre los trabajadores, pues

\footnotetext{
${ }^{48}$ Cfr. Entrevista realizada a Odalys Torrens Álvarez, jefa del Departamento de Seguridad y Salud en el Trabajo del Ministerio de Trabajo y Seguridad Social, en el periódico Trabajadores, 9 de junio de 2014.

${ }^{49}$ Véase Capella, Juan Ramón, Fruta prohibida. Una aproximación histórico-teorética al estudio del derecho y del Estado, Madrid, Trotta, 1999, p. 223.
} 
prefieren ignorar las condiciones actuales de los puestos de trabajo a cambio de asegurar otros aspectos de la relación jurídica laboral. Esta debilidad de la cultura acerca de las condiciones de trabajo incide directamente contra los trabajadores y por consiguiente se convierte en un freno a la formación de una conciencia ecológica en el ámbito productivo.

En estos momentos, los medios de difusión masiva han comenzado a ejercer función divulgativa en materia de seguridad y salud en el trabajo, pero le corresponde a la comunidad y sobre todo a la científica jurídica, contribuir no sólo a la información sino al conocimiento total en relación con esta temática, máxime cuando nuestro país lleva a cabo la actualización del modelo económico cubano y con esto la perfección de nuestro sistema empresarial, lo que traerá consigo el desarrollo de una cultura empresarial y por ende la utilización de trabajadores con un vasto nivel cultural.

\section{Correspondencia de los sistemas de gestión de la seguridad}

\section{y salud en el trabajo con el contexto económico}

El contexto económico es el que determina el surgimiento, desarrollo y actualización de determinada rama del derecho, pues éste no es una ciencia estática o inmovible, sino que requiere estar en constante cambio con el fin de poder darle respuesta a las disímiles situaciones que se producen en la sociedad; ejemplo de ello lo constituye el derecho laboral y en su interior la seguridad y salud en el trabajo; aislarlo de su realidad social traería consigo entrar al plano de la subjetividad y por ende eliminar la esencia social que tiene esta rama del derecho.

En este sentido, el modelo económico cubano, a partir de la aprobación de los Lineamientos de la Política Económica y Social del Partido y la Revolución, persigue como objetivo construir una sociedad socialista próspera y sostenible, donde se reconoce y se promueve además de la empresa estatal socialista como forma principal en la economía cubana otras formas de gestión no estatal y que tiene como fundamento esencial, elevar la eficiencia del trabajo, sobre la base de la creación de la condiciones óptimas para que los trabajadores puedan desarrollar su actividad laboral sin riesgo para su salud o se ponga en 
peligro su vida. De aquí se deriva la necesidad de que los SGSST implementados en las empresas estén atemperados con el contexto económico del país y sobre todo con la realidad económica y social de la empresa, lo que traerá consigo una mayor protección a los que ofrecen su fuerza de trabajo.

Unido a esto se añade la necesidad de que los SGSST estén acordes con las políticas trazadas en la empresa, políticas que guardan relación con el objeto social de la empresa, pues en muchos de los casos, la política de seguridad y salud en el trabajo en las empresas está alejada de las condiciones reales de la misma, en el sentido de que no recogen todos los riesgos laborales a los que están expuestos los trabajadores en cada una de las áreas de trabajo, poco compromiso de la dirección de la empresa como de las áreas en relación con la seguridad y salud en el trabajo y la existencia de una inadecuada planificación de la asignación de los recursos para la protección y seguridad en el trabajo.

Tal cuestión entra en contradicción con el ideal de lograr una empresa socialmente responsable, en el sentido de que si una empresa solamente se concentra en el aspecto objetivo (cumplimiento de su objeto social y el ingreso de ganancias a la economía nacional) y se olvida del aspecto subjetivo (sus trabajadores y el conjunto de acciones en pos de su bienestar), esto trae consigo que no funcione como un sistema integrado de gestión de la calidad, lo que la convertiría en economista sin tener en cuenta lo que en la actualidad tiene un impacto en el contexto económico, el llamado valor agregado de las empresas.

Por ello no basta con tener disposiciones legales o con tener implementado un SGSST en una empresa, sino que se hace necesario que los mismos estén a tono con el contexto económico del sistema empresarial en sentido general y en particular al de cada empresa, lo que coadyuvará al logro de la eficiencia económica; por tanto, el SGSST será eficiente si está en consonancia con las condiciones reales de la empresa, conducente a lograr una mayor protección de los trabajadores y por ende el OJLC será operante si está atemperado a la realidad social sobre la base del principio de la objetividad normativa.

\section{Enfoque intra e interdisciplinario en la creación e implementación}


de los sistemas de gestión de la seguridad y salud en el trabajo

Es apreciable una carencia epistemológica intra e interdisciplinaria en el tratamiento jurídico a los SGSST, dada en las incongruencias existentes entre su proceso de creación e implementación con la realidad social de las empresas. En tal sentido desde las ciencias jurídicas y especialmente la laboral, deben realizarse estudios interdisciplinarios que precedan y evalúen la formulación normativa en relación con esta materia así como incorporarse en los métodos de interpretación e integración del derecho.

A tono con esto, la profesora Guevara Ramírez ${ }^{50}$ refiere que en relación con este aspecto, las ciencias jurídicas consideran que no tiene contenido jurídico como para el desarrollo de investigaciones, dígase maestría o doctorado, cuando lo que pasa es que no le han prestado suficiente atención al medio ambiente laboral y los riesgos existentes, tanto físicos, químicos, radiológicos, como ocupacionales y sicosociales. De igual manera manifiesta que cuando hablamos de derecho lo vemos como un apartado muy puro y sin la connotación sociológica que tiene, al ver al ser humano como lo que es, un ser biosicosocial que merece muchísima atención, porque de la seguridad y salud en el trabajo, de la atención que se le preste, de las restricciones legales que se establezcan, lograremos que sea más duradero como ciudadano, por lo que un enfoque sociológico de esta problemática debe tomar en cuenta los criterios anteriores, debe proyectarse a evaluar la conducta y el grado de participación de los trabajadores en los procesos de la empresa así como el papel responsable de esta última en la satisfacción de las necesidades sociales basadas en los tres aspectos fundamentales: económico, social y medio ambiente.

Lograr un trabajo protegido se convierte en una máxima en aras de disminuir los efectos de un fenómeno, que en nuestro caso se hace más complejo por las evidentes carencias económicas unidas a las insuficiencias derivadas de la actuación humana, tanto de los directivos encargados de hacer cumplir las normativas como de los trabajadores y

\footnotetext{
${ }^{50}$ Conversación sostenida con la profesora Lydia Guevara Ramírez, mediante correo electrónico el 3 de octubre de 2014.
} 
de otras que no requieren de inversiones sino de mayor voluntad e iniciativa para su eliminación, unido al conocimiento de otras ciencias como la economía y la ingeniería industrial (ergonomía del trabajo) lo que coadyuvaría a la implementación de un correcto SGSST y con esto una mayor protección de la fuerza de trabajo y por ende una empresa socialmente responsable.

Todo esto nos permitió plantear los presupuestos anteriores que tributarán al perfeccionamiento de dichos sistemas, lo que va a permitir la transformación del entorno donde está enclavada la empresa y mayor protección a los trabajadores.

\section{CONCLUSIONES}

1. La seguridad y la salud en el trabajo ha sido un tema de interés en las diferentes etapas del desarrollo histórico de la sociedad, por lo que la formalización de sus métodos, fines y cuerpo teórico es el resultado de la producción investigativa de profesionales de diferentes especialidades. Sin embargo todavía existen limitaciones que deben ser superadas con la misma rapidez con que se ha desarrollado en los siglos XX y XXI, caracterizados por las nuevas necesidades derivadas del empleo de las TIC, de su relación con la RSE así como los nuevos contextos laborales donde predominan las exigencias mentales sobre las físicas.

2. En el derecho internacional con independencia de la diversidad que adoptan las normativas específicas sobre la seguridad y salud en el trabajo, se evidencia su tendencia regulativa así como el reconocimiento en normativas especiales propias del ámbito del derecho del trabajo de sus elementos, fines, métodos y su relación con la RSE. En cambio, en el derecho comparado, las acciones en torno a la SST y su relación con la RSE dependen de las condiciones socioeconómicas y políticas de cada Estado, por lo que la tendencia en las regiones analizadas es la de regular en cuerpo normativo lo concerniente a ambas categorías jurídicas.

3. En el ordenamiento jurídico laboral cubano se evidencia el reconocimiento de la seguridad y salud en el trabajo, tutelando la protección a los trabajadores frente a determinados riesgos laborales. Pero en la norma jurídica que conforma este ordenamiento, a pesar de 
permitir la autonomía de que cada organismo actualice sus procedimientos en esta materia y que cada empresa o institución adecue las regulaciones a sus necesidades, se aprecia una asistematicidad de los principios de la SST reconocidos por la OIT, lo que atenta sin dudas contra la seguridad jurídica de esta institución, la protección de los trabajadores y a una adecuada aplicación de la RSE.

4. Las empresas seleccionadas del municipio Bayamo acogidas al perfeccionamiento empresarial, cuentan con la implementación de manera positiva de manuales y planes de prevención de riesgos referentes al sistema de gestión de la seguridad y salud en el trabajo con el objetivo de lograr un medio ambiente laboral adecuado para la realización de las actividades labores previstas. No obstante es insuficiente por no existir una sistematicidad de los principios de la seguridad y salud en el trabajo en nuestro OJLC, el control sistemático de los jefes de las entidades a las actividades previstas en los SGSST, la previsión de los riesgos incidentes en el ámbito laboral, la cultura empresarial en torno a la seguridad y salud en el trabajo; a esto se une la deficiente participación, ejecución y control por parte de la organización sindical en los SGSST.

\section{RECOMENDACIONES}

A la Comisión de Asuntos Jurídicos y Constitucionales de la Asamblea Nacional del Poder Popular:

— Que en futuras modificaciones al capítulo I "Disposiciones generales", sección primera "Fundamentos y principios del derecho del trabajo" del Código de Trabajo, se reconozca en el artículo 20., los principios generales del derecho laboral, y en particular los de la seguridad y salud en el trabajo, en aras de eliminar los rasgos de asistematicidad que presenta nuestro ordenamiento jurídico laboral.

— Que se incluya en el capítulo XI "Seguridad y salud en el trabajo", sección primera "Disposiciones generales" del Código de Trabajo, la metodología y aspectos esenciales a tener en cuenta a la hora de concebir los sistemas de gestión de la seguridad y salud en el trabajo, en aras de su adecuada implementación y control en el sistema 
empresarial cubano.

Al Ministerio de Trabajo y Seguridad Social:

- Que sea incluida en sus líneas de trabajo, la revisión de las insuficiencias derivadas del análisis efectuado al ordenamiento jurídico laboral, a los efectos de perfeccionar el marco legal general aplicable en materia de SST, en especial, establecer las normas y procedimientos para su instrumentación.

A las facultades de derecho del país:

— Que atendiendo a los resultados de la investigación y las insuficiencias examinadas en su contenido, se inserte a la actividad de posgrado en materia de seguridad y salud en el trabajo, haciendo especial énfasis en los postulados garantes de esta actividad en el sistema empresarial cubano.

- Que en investigaciones posteriores vinculadas a la materia laboral, y en especial sobre la seguridad y salud en el trabajo, se profundice en las vertientes dogmáticas del tema tratado por su importancia y repercusión en el cumplimiento de las normativas tanto a nivel nacional como internacional, para una mayor protección de la fuerza de trabajo.

\section{BIBLIOGRAFÍA}

Alfaro RojAS, Adriana María, Análisis doctrinario y jurisprudencial de las enfermedades incapacitantes como riesgo de trabajo y los posibles efectos en la suspensión del contrato de trabajo, tesis para optar por el grado de Licenciatura en Derecho, Facultad de Derecho, Universidad de Costa Rica, 2011.

Alfonso A., Juan Luis, Modelo de gestión de la responsabilidad social corporativa directa. Estudio de caso: cooperativa de producción agropecuaria "Camilo Cienfuegos", tesis presentada en opción al grado científico de Doctor en Ciencias, Pinar del Río, 2008.

ARAGÓn, J y Rocha, F., La dimensión laboral de la responsabilidad social de las empresas, Madrid, Cuadernos de Información Sindical, 2005.

ArChel Domenech, Pablo y Husillos CARQués, Javier, “Últimos desarrollos de 
la RSE en España. ¿Un avance hacia la sostenibilidad?", Revista Economía Pública, Social y Cooperativa, España, CIRIEC, núm. 65, agosto de 2009.

ARCiEnAga ÁvilA, Federico Guillermo, Derechos fundamentales y el derecho del trabajo en el siglo XXI, Congreso Mundial de la Sociedad Internacional de Derecho del Trabajo y la Seguridad Social, Montevideo, septiembre de 2003.

Arturo de Diego, Julián, Manual de derecho del trabajo y de la seguridad social, 5a. ed., Buenos Aires, Lexis-Nexis/Abeledo-Perrot, 2002.

AyAla Del Pino, Cristina, “La prevención de riesgos laborales en la relación especial del servicio del hogar familiar", Saberes, Revista de Estudios Jurídicos, Económicos y Sociales, vol. 5, Madrid, Universidad Alfonso X El Sabio, Facultad de Estudios Sociales, 2007.

BARAÑANo Cid, Margarita, Contexto, concepto $y$ dilemas de la responsabilidad social de las empresas transnacionales europeas: una aproximación sociológica, Cuadernos de Relaciones Laborales, vol. 27, núm. 1, 2009.

BetAnCourt, Oscar, "Enfoque alternativo de la Salud y Seguridad en el Trabajo", IESS, Prevención es Desarrollo, año 1, núm. 1, Quito, julio de 2007.

CAAMAL CAUICH, Ignacio et al., Tendencias actuales de la responsabilidad social en las empresas en México, 2010.

CAPELLA, Juan Ramón, Fruta prohibida. Una aproximación históricoteorética al estudio del derecho y el Estado, Madrid, Trotta, 1999.

CAPECE, S., “Lectura económico-finanziaria della responsabilitá sociale dell impresa", en GRECCO, P., Lavoratori e impresa socialmente responsabile, Turín, G. Giappichelli, 2007.

COMISIÓN DE LAS COMUNIDAdES EUROPEAS, Comunicación de la comisión relativa la responsabilidad social de las empresas: una contribución empresarial al desarrollo sostenible, Bruselas, 2002.

COMISIÓN EUROPA, Corporate social responsability. Nacional public policies in the European Union, Luxemburgo, 2007. 
Collado LUIS, Santiago, "Prevención de riesgos laborales. Principios y marco normativo", Revista de Dirección y Administración de empresas, núm. 15, diciembre de 2008.

Cordero MÁrquez, Beatriz, "Auditoría de un sistema de gestión de la responsabilidad social corporativa. RS10 sistema de gestión de la responsabilidad social", Boletín del Centro de Investigación de Economía y Sociedad, núm. 84, Barcelona, octubre de 2010.

CORDURAS, Alicia, Responsabilidad social empresarial y emprendimiento en España, Business School para la Dirección General de Política de Pymes.

CORREA, María Emilia et al., "Responsabilidad social corporativa en América Latina: una visión empresarial", Serie Medio Ambiente y Desarrollo, Santiago de Chile, núm. 85, División de Desarrollo Sostenible y Asentamientos Humanos, abril de 2004.

COS EGEA, Manrique, La responsabilidad administrativa del empresario en materia de prevención de riesgos laborales: estudio de las infracciones muy grave, España, Murcia-Departamento Derecho del Trabajo y de la Seguridad Social, Facultad de Derecho, 2009.

CRUZ PÉREZ, Yudemir, Metodología para la elaboración de estrategias de marketing forestal sostenible en Cuba, tesis presentada en opción al grado científico de Doctor en Ciencias Forestales, Universidad de Pinar del Río, 2010.

Cruz Romera, Dunia Esther, Diagnóstico al Sistema de Gestión de la Seguridad y Salud Ocupacional en la empresa comercializadora y distribuidora de medicamentos. Droguería Holguín, Facultad de Ingeniería Industrial y Turismo, Universidad de Holguín “Oscar Lucero Moya", 2009.

Cruz Trujillo, Acela y Senarega CocA, Caridad, ambiente laboral, seguridad, higiene y salud, La Habana, Científico-Técnica, 2012.

CUESTA GONZÁlEZ, M., “La confianza de la información sobre responsabilidad social corporativa AECA", Revista de la Asociación Española de Contabilidad y Administración de Empresas, núm. 80, 2007.

Cuesta GonzÁlez, Marta de la y Valor Martínez, Carmen, “Responsabilidad 
social de la empresa. Concepto, medición y desarrollo en España", Boletín Económico de ICE, núm. 2755, enero de 2003.

Río HeRnÁNDEZ, Mirtha A. del, “La investigación jurídica en opción a grados científicos", Revista Cubana de Derecho, IV Época, núm. 39, Editora Unijuris, enero-junio de 2012.

DOMÍNGUEZ MARTIN, R., “La responsabilidad social global empresarial (RSGE): el sector privado y la lucha contra la pobreza", Revista del Ministerio de Trabajo e Inmigración, núm. 76.

Estrada Molina, Odiel, Alternativa informática para la evaluación de riesgos laborales, La Habana, Universidad de las Ciencias Informáticas, junio de 2012.

FAUCHERE, B., "La responsabilidad social de las empresas y los códigos de conducta ¿nuevos retos o viejos debates?", Lan Harremanak, 2006-I, núm. 14.

FLAVIO FUENTES, María Lara Goyburu, La responsabilidad social empresarial. ¿sólo un discurso? Comisión Económica para la América Latina y el Caribe, Santiago de Chile, agosto de 2006, documento proyecto.

Flor FeRnáNDEZ, María Luisa de la, Análisis de la regulación jurídico-laboral de los riesgos psicosociales, Universidad de Cádiz, mayo de 2006.

García Perdiguero, T., La responsabilidad social de las empresas en un mundo global, Barcelona, 2005.

García Selgas, F., Bosquejo de una teoría de la fluidez social. Política y Sociedad, vol. 43, núm. 2, 2006.

-_- Sobre la fluidez social: elementos para una cartografía. Centro de investigaciones sociológicas, Madrid, 2006.

GIL FUndorA, Silvia et al., Seguridad, salud y medio ambiente de trabajo y su vínculo con otros sistemas de la gestión empresarial, Cienfuegos, 2004.

Gómez ArAndA, Rodolfo, Derecho laboral I. Red Tercer Milenio, Estado de México, 2012.

GONZÁLEZ FERNÁNDEZ, María Teresa, Impacto y percepción de la 
responsabilidad social corporativa (RSC): Análisis del sector financiero en España, tesis de grado en Administración y Dirección de Empresas, Facultad de Ciencias Económicas y Empresariales, Universidad de León, curso 2011-2012.

GonzÁlez GonzÁlez, Nury Amparo, Diseño del sistema de gestión en seguridad y salud ocupacional, bajo los requisitos de la norma NTCOHSAS 188001 en el proceso de fabricación de cosméticos para la empresa WILCOS, S. A., tesis para optar por el título de Ingeniería Industrial, Bogotá, Pontificia Universidad Javeriana, Facultad de Ingeniería, 2009.

Guevara Ramírez, Lidia, Una mirada al mundo del trabajo. Recopilación monográfica de reflexiones sobre violencia laboral, condiciones $y$ medio ambiente en el trabajo, Universidad Autónoma del Estado de México, Campus Universitario Siglo XXI, Facultad de Derecho, s.f.

- - - "Reflexiones al vuelo sobre la plaga del siglo XXI en las relaciones laborales", Ponencia presentada al V Encuentro Interamericano de Derecho Laboral y Seguridad Social, La Habana, 21-24 de octubre de 2005.

Guía del empresario individual, catálogo general de publicaciones oficiales http:// publicaciones.administración.es, Dirección General de Política de la Pequeña y Mediana Empresa, marzo de 2007.

HeRnÁNDEZ SÁNCHEZ, Felipe, Responsabilidad legales del empresario y del técnico de prevención en materia de prevención de riesgos laborales, España, octubre de 2008.

Hernández, Tatiana e ISAAC Godines, Cira, Procedimiento para el diseño e implantación de un sistema de gestión integrado en el BIOCEN, 2007.

KEYNES, Jhon Maynard, La teoría general sobre el empleo, el interés y el dinero, La Habana, Instituto del Libro, 1968.

“La opinión y valoración de los consumidores sobre la Responsabilidad Social de la Empresa en España", septiembre de 2010, Confederación de Consumidores y Usuarios.

“La responsabilidad social empresarial de la Pymes. Ejemplos prácticos 
para fomentar la competitividad de las pymes. Comisión Europea", Dirección general de empresa e industria, 2007.

LABRADA MARRO, Dagoberto, Diagnóstico al sistema de gestión de la seguridad y salud ocupacional en la empresa productora $y$ distribuidora de alimento Calixto García, Facultad de Ingeniería Industrial y Turismo, Universidad de Holguín "Oscar Lucero Moya", curso 2008-2009.

LACASA, José María, La responsabilidad social empresarial, bien entendida, no es regulación, disponible en http://Www.cioe.es fecha noticia/htm/3id=71228 (consultada el 23 de abril de 2014).

LANG, Susanne y Solmes Nebeleng, Frank, La responsabilidad social como estrategias de negocios, trad. de Katrin Zinsmeister, Buenos Aires, Nueva Sociedad, noviembre de 2006.

LIBRO VERDE, Fomentar un marco europeo para la responsabilidad social de las empresas, Comisión de las Comunidades Europeas, Bruselas, 18 de julio de 2001.

LIZCANO ÁlVAREZ, José Luis, “Responsabilidad social corporativa y confianza en las organizaciones. Una aproximación al Cuadro de Mando para la Responsabilidad Social (CMRS)", Papeles de Ética, Economía y Dirección, núm. 8, 2003.

Manguela díAZ, Gabino y Barreras Ferrán, Ramón, “La seguridad de un trabajo seguro", Periódico Trabajadores, 9 de junio de 2014.

MARINo Segovia, Amparo, Responsabilidad social corporativa: su dimensión laboral, Universidad de La Mancha, Castilla.

Martínez Rodríguez, Rosa del C., Diseño de un sistema de gestión de seguridad y salud laboral para el Instituto Nacional de Higiene "Rafael Rangel", tesis para optar al grado de Especialista en Gerencia de Servicios Asistenciales en Salud, Caracas, Universidad Católica Andrés Bello, octubre de 2008.

MARTínez, Rosa, Diseño de un sistema de gestión de seguridad y salud laboral para el Instituto Nacional de Higiene Rafael Rangel, trabajo especial de grado de Especialista en Gerencia de Servicios Asistenciales 
de Salud, Caracas, Universidad Católica Andrés Bello, 2008.

Merino, A., Igualdad de género, empresa y responsabilidad social, Albacete, Bomarzo, 2009.

Mertens, Leonard y FALCón, Mónica, Salud y seguridad en el trabajo y el papel de la formación en México (con referencia a la industria azucarera). Red de Reestructuración y Competitividad, Santiago de Chile, División de Desarrollo Productivo y Empresarial, mayo de 2004.

Miranda Hernández, Celia, Diseño de un sistema integrado de gestión de calidad, medio ambiente, seguridad y salud en el trabajo en la empresa de plaguicidas "Juan Luis Rodríguez Gómez", tesis en opción al grado científico de Máster en Ciencias Técnicas, Instituto Superior Politécnico "José Antonio Echeverría", Facultad de Ingeniería Industrial, junio de 2012.

MORENO JimÉnEZ, Bernardo y BÁEZ LEón, Carmen, Factores y riesgos psicosociales, formas, consecuencias, medidas y buenas prácticas, Madrid, noviembre de 2010.

MuÑoz DuEÑAS, María del Pilar, La responsabilidad social de las empresas: una variable más a considerar en la cultura empresarial, Facultad de Ciencias Económicas y Empresariales, Universidad de Vigo, 2005.

MuÑOz HidAlgo, Isabel Teresa, La conciencia de la empresa forestal: responsabilidad social corporativa, España, mayo de 2011.

NACiMiEnto Jesús, M. M., Ética y actividad empresarial. Cultura y valores éticos en las empresas algarbeñas, Tesis Doctoral, Universidad de Huelva, 2001.

OIT, "Sistema de gestión de la seguridad y salud en el trabajo: una herramienta para la mejora continua", 28 de abril de 2011, disponible en http://www.ilo.org/safeday.

ORLITZKY, Marc et al., “Corporate Social and Financial Perfomance: A MetaAnalysis. Organization Studies", SAGE Publications, Londres, núm. 24, 2003.

Ortiz Aristizabal, Paula Catalina, La responsabilidad social empresarial como base de la estrategia competitiva de $H Z X$, tesis final de grado 
para optar al título de Administrador de Empresa, Bogotá, Pontificia Universidad Javeriana, Facultad de ciencias Económicas y Administrativas, Administración de Empresas, 2009.

PAvó ACOSTA, Rolando, Introducción a la metodología de la investigación jurídica, Santiago de Cuba, Facultad de Derecho, Universidad de Oriente, 2003.

- - - La investigación científica del derecho, Lima, Universidad Inca Gracilazo de la Vega-Nuevos Tiempos, Nuevas Ideas, Fondo Editorial, diciembre de 2009.

Peinado-VARA, Estrella, La responsabilidad social de la empresa en América Latina, cap. 3, Manual de Gestión, Fondo Multilateral de Inversiones, Miembro del Grupo BID.

PÉREZ HeRnández, Laritza, Impacto de la responsabilidad social en el sistema de gestión ambiental, tesis presentada en opción al título de Licenciada en Derecho, Universidad de Granma, Facultad de Ciencias Sociales y Humanísticas, 8 de junio de 2011.

PéReZ HeRnÁNDEZ, Lissette, "Algunas consideraciones a debate sobre la ciencia jurídica y sus métodos", Revista Cubana del Derecho, IV Época, núm. 38, julio-diciembre de 2011.

Plan de Responsabilidad Social de Cruz Roja Española, diciembre 2009.

PodetTI, Humberto A., Instituciones de derechos del trabajo y de la seguridad social, México, UNAM, Instituto de Investigaciones Jurídicas, 1997, cap. 8, p. 139.

Puerta MARTínez, Yusmany y León CLARo, Danaya, La seguridad y salud en el trabajo o medio ambiente laboral, Sancti Spíritus, 2008.

RACCATTI, Octavio, Las transformaciones en el mundo del trabajo y el derecho laboral, Instituciones de Derecho del Trabajo y la Seguridad Social, Facultad de Derecho.

- _- “Tercerización: exteriorización del empleo y descentralización productiva", Revista Derecho Laboral, Montevideo, t. XL, núm. 185, enero-marzo de 1997. 
RAMíreZ Ávila, Zarahí, Implementación del sistema de gestión de la seguridad y salud en el trabajo en la empresa de materiales de la construcción de Holguín teniendo en cuenta la NC 18001: 2005, trabajo de Diploma, Facultad de Ingeniería Industrial y Turismo, Universidad de Holguín “Oscar Lucero Moya”, 2009.

"Seguridad", Revista MAPFRE, Madrid, MAPFRE S. A., año 26, núm. 101, primer trimestre de 2006.

Revista Seguridad y Medio Ambiente, Madrid, Fundación MAPFRE, Instituto de Prevención, Salud y Medio Ambiente, Monte del Pilar, s/n, año 28, núm. 110, segundo trimestre de 2008.

- - - Madrid, Fundación MAPFRE, Instituto de Prevención, Salud y Medio Ambiente, Monte del Pilar, s/n, año 28, núm. 111, tercer trimestre de 2008.

- - - Madrid, Fundación MAPFRE, Instituto de Prevención, Salud y Medio Ambiente, Monte del Pilar, s/n, año 29, núm. 114, segundo trimestre de 2009.

- - - Madrid, Fundación MAPFRE, Instituto de Prevención, Salud y Medio Ambiente, Monte del Pilar, s/n, año 29, núm.115, tercer trimestre de 2009.

- - - Madrid, Fundación MAPFRE, Instituto de Prevención, Salud y Medio Ambiente, Monte del Pilar, s/n, año 29, núm. 116, cuarto trimestre de 2009.

- - - Madrid, Fundación MAPFRE, Instituto de Prevención, Salud y Medio Ambiente, Monte del Pilar, s/n, año 30, núm. 117, primer trimestre de 2010.

- - - Madrid, Fundación MAPFRE, Instituto de Prevención, Salud y Medio Ambiente, Monte del Pilar, s/n, año 30, núm. 118, segundo trimestre de 2010.

_-_, Madrid, Fundación MAPFRE, Instituto de Prevención, Salud y Medio Ambiente, Monte del Pilar, s/n, año 30, núm. 120, cuarto trimestre de 2010.

- - - Madrid, Fundación MAPFRE, Instituto de Prevención, Salud y 
Medio Ambiente, Monte del Pilar, s/n, año 31, núm. 121, primer trimestre de 2011.

- - - Madrid, Fundación MAPFRE, Instituto de Prevención, Salud y Medio Ambiente, Monte del Pilar, s/n, año 31, núm. 122, Segundo Trimestre de 2011.

- - - Madrid, Fundación MAPFRE, Instituto de Prevención, Salud y Medio Ambiente, Monte del Pilar, s/n, año 31, núm. 124, cuarto trimestre de 2011.

- - - Madrid, Fundación MAPFRE, Instituto de Prevención, Salud y Medio Ambiente, Monte del Pilar, s/n, año 32, núm. 125, primer trimestre de 2012.

- - - Madrid, Fundación MAPFRE, Instituto de Prevención, Salud y Medio Ambiente, Monte del Pilar, s/n, año 32, núm. 126, segundo trimestre de 2012.

- - - Madrid, Fundación MAPFRE, Instituto de Prevención, Salud y Medio Ambiente, Monte del Pilar, s/n, año 32, núm. 127, segundo trimestre de 2012.

Reyes MendozA, Libia, Derecho laboral. Red, Tercer Milenio, Estado de México, 2012.

ReYNo Momberg, Manuel, Responsabilidad social empresarial (RSE) como ventaja competitiva, tesis presentada en opción al grado de Magíster en Gestión Empresarial, Universidad Técnica Federico Santa María, Departamento de Industrias, septiembre de 2006.

RODRÍGUEZ, Carlos Aníbal, Los convenios de la OIT sobre seguridad y salud en el trabajo. Una oportunidad para mejorar las condiciones y el medio ambiente de trabajo, Buenos Aires, Oficina de la OIT en ArgentinaCentro Internacional de Formación de la OIT, Turín-CIF, 2009.

ROJAS CASAS, Ricardo D., Los accidentes del trabajo en la Industria Azucarera de Holguín, tesis presentada en opción al título académico de Máster en Matemática Aplicada e Informática para la Administración, Universidad de Holguín “Oscar Lucero Moya”, Facultad de Ingeniería Industrial, Holguín, 2001. 
RojAS MuÑoz, Alfonso Lucas, Responsabilidad social empresarial: su origen, evolución y desarrollo en Colombia, Universidad Santiago de Chile, 2010.

Rojas Muñoz, Alfonso lucas y Olaya GarcerÁ, Jorge Eliecer, Responsabilidad social empresarial: su origen, evolución y desarrollo en Colombia, Universidad Santiago de Cali, 2009.

RUIZ MuÑOz, Miguel, Un apunte crítico sobre la responsabilidad social corporativa (RSC/RSE), Madrid, Redur 9, diciembre de 2011.

SANTANA PASCuAL, Kenia, Diseño e implantación del sistema integrado de gestión de calidad, medio ambiente, seguridad y salud en el trabajo, tesis en opción al grado científico de Máster en Ciencias Técnicas, Instituto Superior Politécnico "José Antonio Echeverría", Facultad de Ingeniería Industrial, junio de 2012.

SCHULzE, Francisca y PSzolLA, Valerie, Situación de la responsabilidad social empresarial en Europa (Status of the Corporate Social Responsability in Europe).

TORRENS Álvarez, Odalys, La gestión de seguridad y salud en el trabajo en el marco de la gestión de los recursos humanos en la empresa, La Habana, Ministerio de Trabajo y Seguridad Social, 2003.

VARGAS SÁNCHEZ, Alfonso, Responsabilidad social corporativa y dirección de los recursos humanos, Universidad de Huelva-Departamento de Dirección de Empresas y Marketing, 2006.

VARIOS AUTORES, Comparación internacional de sistemas de salud y seguridad laboral, Santiago de Chile, OIT, 2011.

-_- Enciclopedia de salud y seguridad en el trabajo, Barcelona, Gestión Editorial Chantal Dufresme, 1998.

-_- Estudios sobre responsabilidad social en el sector financiero de Perú y Brasil: Análisis comparativo, Lima, Serie de Estudios-Grupo Financiero-Programa Laboral de Desarrollo-PLADES, núm. 3, marzo de 2008.

_-_, Guía para la evaluación y control de riesgos laborales en las pequeñas y medianas empresas del sector de artes gráficas, Madrid, 
2001.

_-_- La responsabilidad social de las empresas en el combate de la corrupción, Brasil, 2010.

- - - Las consecuencias de la organización del trabajo en la salud laboral en la empresa: estudio de las variables que intervienen en la aparición de riesgos psicosociales, España, Universidad de Salamanca, 2011.

VelÁzQUez Zaldívar, Reynaldo, Modelo de mejora continua para la gestión de la seguridad e higiene ocupacional. Aplicaciones en empresas de la industria alimenticia, tesis presentada en opción al grado científico de Doctor en Ciencias Técnicas, La Habana, Instituto Superior Politécnico "José Antonio Echeverría", Facultad de Ingeniería Industrial, Departamento de Ingeniería Industrial, 2002.

Viamontes Guilbeaux, Eulalia de la C., Derecho laboral cubano. Teoría y legislación, La Habana, Félix Varela, 2007.

Villabella Armengol, Carlos Manuel, “Prosiguiendo el debate: los métodos en la investigación jurídica", Revista Cubana del Derecho, IV Época, núm. 40, julio-diciembre de 2012.

ViVes, Antonio y PeinAdo-Vera, Estrella, La responsabilidad social de la empresa en América Latina, Publicación del Banco Internacional de desarrollo, mayo de 2011.

Sitios web consultados

http://Www.gemspain.com/Mis\%20archivos/Informes\%20Especiales/Resp onsabilidad\%20social\%20y\%20emprendimiento\%20en\%20Espana_final $-1$. pdf.

http://WWw.cruzroja.es/p/s/portal30/docs/PAGE/RESPONSABILIDADSOCIA L/CRUZ\%20ROJA\%20ESPANOLA\%20\%20PLAN\%20RESPONSABILIAD\%20SOCIAL.PDF. http://WWW20.gencat.cat/docs/rscat/03\%20\%20Ambit\%20Persones/Docu ments/Arxius/Informe\%20RSE\%202010.pdf. 
Esta revista forma parte del acervo de la Biblioteca Jurídica Virtual del Instituto de Investigaciones Jurídicas de la UNAM

http://WWw.ciesi.org/docs/cirseds-ciesi-folleto.pdf.

http://WWw.csr-in-smes.eu/downloads/brochure_spanish.pdf.

http://wWw.opel.es/content/dam/Opel/Europe/spain/hq/es/03_Owners/08 _Recycling/Memoria_Responsabilidad_Corporativa_GM_Espana.

http://wWw.revistasice.info/cachepdf/BICE_2755_0719_843B2AFA16833B D45F65BF48332D2587.pdf.

http://Www.forestales.net/archivos/forestal/pdfs\%2054/CT4-La-

conciencia-de-la-empresa-forestal.pdf.

https://WWw.google.es/\#q=RESPONSABILIDAD+SOCIAL+CORPORATIVA $+\gamma+$. http://WWw.proyectocrearse.com/guia/guia_crearse_1_RSE_web.pdf.

http://Www.uria.com/documentos/publicaciones/3442/documento/dgoU M.pdf?id=3997.

https://buleria.unileon.es/xm/ui/bitstream/handle/10612/1857/09797464 Q_GADE_julio2012.pdf?sequence=1.

http://WWW.ciriec-revistaeconomia.es/banco/6503_Archel_y_Husillos.pdf. http://WWW.mcdonalds.es/sites/default/files/article/informe_mcd_2011.pd $f$.

http://eur-lex.europa.eu/LexUriServ/site/es/com/2001/com2001_0366es0 1.pdf. 